Portland State University

PDXScholar

$1-1-2011$

\title{
Do "Clickers" Improve Student Engagement and Learning in Secondary Schools?
}

Andrew James Mankowski

Portland State University

Follow this and additional works at: https://pdxscholar.library.pdx.edu/open_access_etds Let us know how access to this document benefits you.

\section{Recommended Citation}

Mankowski, Andrew James, "Do "Clickers" Improve Student Engagement and Learning in Secondary Schools?" (2011). Dissertations and Theses. Paper 144.

https://doi.org/10.15760/etd.144

This Thesis is brought to you for free and open access. It has been accepted for inclusion in Dissertations and Theses by an authorized administrator of PDXScholar. Please contact us if we can make this document more accessible: pdxscholar@pdx.edu. 
Do "Clickers" Improve Student Engagement and Learning in Secondary Schools?

by

Andrew James Mankowski

A thesis submitted in partial fulfillment of the requirements for the degree of

\author{
Master of Science in Teaching \\ in \\ General Science
}

Thesis Committee:

Michael Flower, Chair

Liza Finkel

Melissa Potter

Portland State University

2011 
ABSTRACT

There is a need in classrooms to engage students and maintain their interest in course content. A recent type of interactive technology, known as a "clicker," has shown potential to increase student engagement, performance, and participation in the classroom when used effectively. Peer instruction, a type of student to student interaction in which pairs or small groups of students discuss their answers to questions before responding, is often used in conjunction with clickers, and may account for the perceived effectiveness of these tools. The purpose of this study is to determine the clicker's effectiveness in increasing learning and increasing student engagement in secondary classrooms, while controlling for their use during peer instruction. Two classrooms were examined $(\mathrm{n} \sim 15$ for each classroom) in which 1 classroom used clickers integrated with peer instruction activities, while the other classroom only did the peer instruction activities. The findings of this study showed no significant difference in student learning, a small increase in student engagement, and a positive student reaction to the clicker's potential and use in the classroom. 
Table of Contents

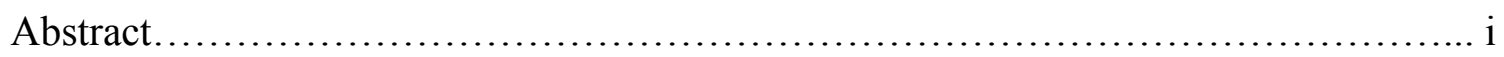

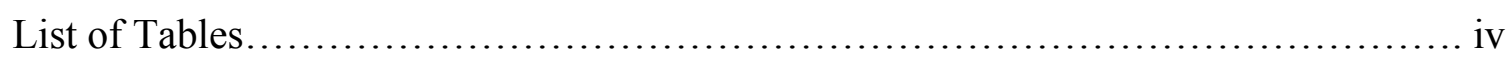

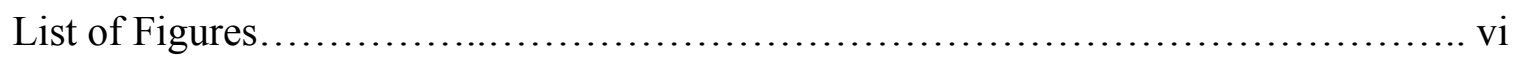

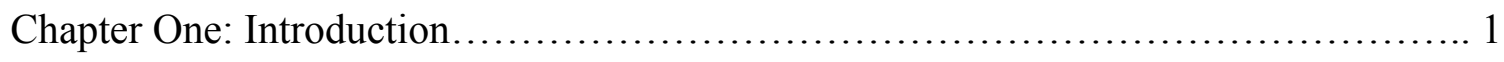

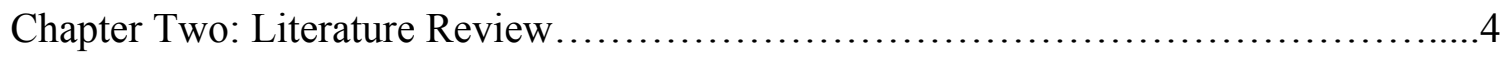

Active Participation and Interactive Technology..........................4

Clickers.........................................................

Peer Instruction. ................................................... 12

Chapter Three: Method....................................................15

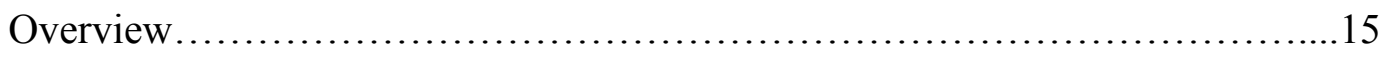

Participants...................................................... 17

Treatment........................................................17

Instruments ..................................................... 20

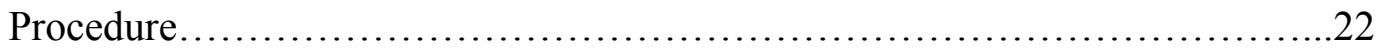

Chapter Four: Results.................................................25

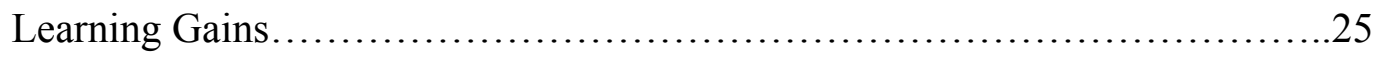

Student Engagement - Quantitative....................................28

Student Engagement - Qualitative....................................52

Chapter Five: Discussion...............................................54

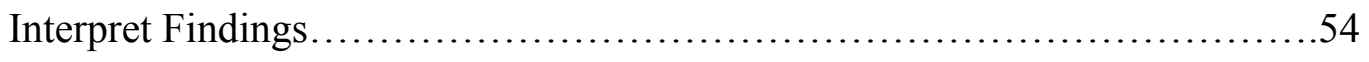

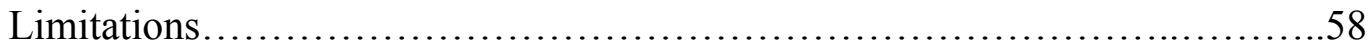

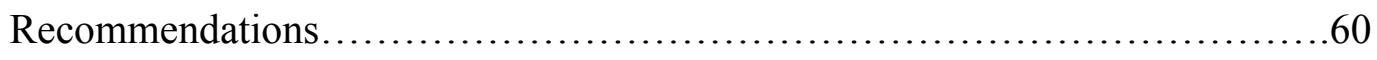


Conclusion.............................................................62

References...........................................................

Appendix A - Assessments, Scoring Guide, Surveys, Interview Transcripts......66

Appendix B - Human Subjects Approval and Application.......................98 


\section{List of Tables}

Table 1: Summary of Methods, Treatment, and Measurements......................16

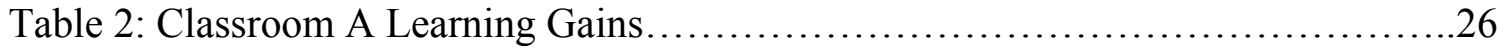

Table 3: Classroom B Learning Gains.......................................27

Table 4: Statistical Tests for Learning Gains of Classroom A and Classroom B........27

Table 5: Number of Questions Asked..............................................29

Table 6: Statistical Tests for Number of Questions Asked...........................29

Table 7: Daily Classroom Discussions Classroom A.............................. 31

Table 8: Statistical Analysis of Daily Classroom Discussions Classroom A.............32

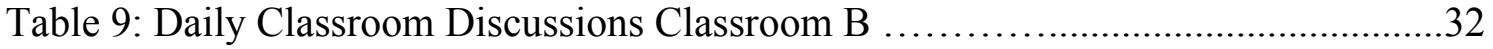

Table 10: Statistical Analysis of Daily Classroom Discussions Classroom B............33

Table 11: Statistical Tests for Daily Discussions for Classroom A and Classroom B...33

Table 12: Daily Self Reflection Participation Classroom A...........................34

Table 13: Statistical Analysis of Daily Self Reflection Participation Classroom A.....35

Table 14: Daily Self Reflection Participation Classroom B.........................35

Table 15: Statistical Analysis of Daily Self Reflection Participation Classroom A.....36

Table 16: Statistical Tests for Daily Self Reflection Participation for Classroom A and Classroom B.........................................................

Table 17: End of Unit Survey Question 1 for Classroom A and Classroom B...........38

Table 18: Statistical Tests for End of Unit Survey Question 1 for Classroom A and

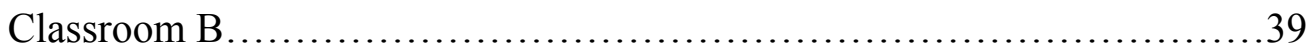

Table 19: End of Unit Survey Question 2 for Classroom A and Classroom B.........40 
Table 20: Statistical Tests for End of Unit Survey Question 2 for Classroom A and Classroom B......................................................... 40

Table 21: End of Unit Survey Question 3 for Classroom A and Classroom B.........42

Table 22: Statistical Tests for End of Unit Survey Question 3 for Classroom A and

Classroom B..................................................42

Table 23: End of Unit Survey Question 4 for Classroom A and Classroom B.........44

Table 24: : Statistical Tests for End of Unit Survey Question 4 for Classroom A and

Classroom B........................................................44

Table 25: End of Unit Survey Question 5 for Classroom A and Classroom B........46

Table 26: Statistical Tests for End of Unit Survey Question 5 for Classroom A and

Classroom B...................................................46

Table 27: End of Unit Survey Question 6 for Classroom A and Classroom B........48

Table 28: Statistical Tests for End of Unit Survey Question 6 for Classroom A and

Classroom B..................................................48

Table 29: End of Unit Survey Question 7 for Classroom A and Classroom B........50

Table 30: Statistical Tests for End of Unit Survey Question 7 for Classroom A and

Classroom B.................................................50 
List of Figures

Figure 1: The Question Cycle, Beatty et al (2004)............................24

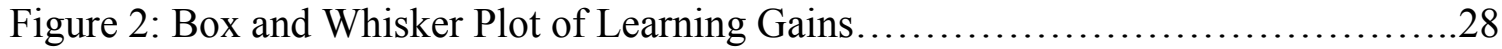

Figure 3: Box and Whisker Plot of Number of Questions Asked...................... 30

Figure 4: Box and Whisker Plot of Daily Discussions........................... 34

Figure 5: Box and Whisker Plot of Daily Self Reflection Participation..................37

Figure 6: Box and Whisker Plot of Survey Question 1............................ 39

Figure 7: Box and Whisker Plot of Survey Question $2 \ldots \ldots \ldots \ldots \ldots \ldots \ldots \ldots \ldots \ldots \ldots \ldots$

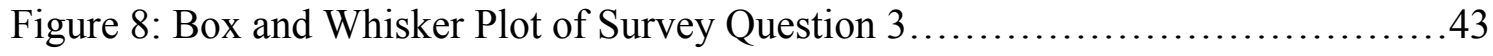

Figure 9: Box and Whisker Plot of Survey Question $4 \ldots \ldots \ldots \ldots \ldots \ldots \ldots \ldots \ldots \ldots \ldots$

Figure 10: Box and Whisker Plot of Survey Question 5.........................47

Figure 11: Box and Whisker Plot of Survey Question $6 \ldots \ldots \ldots \ldots \ldots \ldots \ldots \ldots \ldots \ldots \ldots$

Figure 12: Box and Whisker Plot of Survey Question 7 .........................51 
CHAPTER ONE: INTRODUCTION

\author{
Introduction
}

One form of interactive technology that has been growing in popularity and incorporates active student participation is the Classroom Response System commonly called the "clicker." Clickers are handheld devices, similar in size to a television remote control, that allow students to press buttons and transmit instant individual responses to questions posed by an instructor. Older clicker models use infrared to communicate wirelessly to the system, while newer models use radiofrequency signals. The purpose of this study is to examine the effectiveness of clickers and their use with peer instruction activities in a secondary school.

There is a growing body of literature on clickers, their effectiveness, and how educators perceive them. However, much of this literature is about college classrooms and often it involves large $(n>100)$ class sizes. There is a gap in the understanding of clicker technology and their usage at secondary schools and with smaller classes. The clicker adds anonymity and a game atmosphere to content based classroom questions. The anonymity is an intriguing component of clickers because it is a distinguishing factor that separates clickers from other formative assessment methods such as hand raising and note-cards due to its instantly recordable data and as research shows, more honest feedback (Stowell and Nelson 2007). Since anonymity and clickers are so closely linked, anonymity will not be controlled for in this study, but will be included as part of the operational definition of a clicker. 
The teaching method of peer instruction has been researched in the past couple decades with positive results in student learning. Peer instruction engages students by using activities during class that require them to explain concepts to their fellow classmates. Research by Crouch and Mazur (2001) shows significant increases in student performance and positive student reception to peer instruction activities at the college level. It is for this reason the researcher believes that peer instruction has the potential to be a useful and effective method to integrate with clicker activities in the classroom. In this method two or three students are asked to discuss the answer to a question and agree on a clicker response. Indeed research by Beatty (2008) shows this to be an intriguing method through which clickers can be incorporated into the classroom.

It is possible that clickers have become popular because they lend themselves so well to peer instruction. The purpose of this study is to separate the "clicker effect" from the "peer instruction effect" and determine whether or not use of the clickers makes a difference. The researcher has hypothesized that learning gains and student engagement will increase when clickers are incorporated into a typical $(\mathrm{n} \sim 15)$ secondary school science classroom that uses the peer learning method of peer instruction.

This study was conducted in two science classrooms at a mid-size $(\sim 1200$ students) high school in a Pacific Northwest suburb. Classroom A incorporated clickers into their peer instruction activities, while Classroom B did not. The only independent variable was the use of the clickers. The dependent variables measured were student 
learning gains and student engagement. Learning gains were defined as the difference in knowledge students' exhibit from an initial point in time (measured by a pre test) to an end point in time (measured by a post test) during a unit of instruction. Student engagement was defined as the amount of visible attention and interest students exhibit in the classroom, student centered discussions and class participation, as well as student enjoyment of class activities. Student engagement was measured by daily self-reflection surveys, a daily count of the number and type of questions asked by each individual student, an end of the unit survey, and student interviews. Since the two samples will involve intact classrooms, randomization will not be possible. Consequently this research will use a quasi-experimental contrast group design with pre-post qualitative measures complemented by qualitative observations during the treatments and interviews after the treatments.

This study adds to clicker research at the secondary school level focusing on the question: Are clickers that are used with peer instruction activities effective at improving student learning gains and increasing student engagement in secondary schools? 
CHAPTER TWO: LITERATURE REVIEW

\section{Literature Review}

This literature review is organized in three categories: active participation and interactive technology, clickers, and peer instruction. This review summarizes findings in three areas of educational research relevant to the proposed study.

\section{Active Participation and Interactive Technology}

There is a need in classrooms to engage students and maintain student interest in course content. One way instructors have been attempting to reach their students is by increasing course interest and engagement through active student participation. Galichon and Friedman (1985) found that if students are not interested in the course material, they are less likely to come to class. Research by Narayan et al (1990) found that activities that increase active participation have improved students' performance and Zaremba and Dunn (2004) found that students report greater enjoyment of classes using active learning techniques.

Pemberton et al (2006) also found an increase in student participation and class enjoyment using active learning techniques during review sessions in which interactive computer technologies were used. Their study assessed the effects of LearnStar, a computer-based, interactive trivia-style game, on students' reactions and performance in two different undergraduate psychology courses. The authors' goal was to increase student achievement and satisfaction with these courses. They hypothesized that using 
LearnStar would achieve these goals by increasing students' level of interest, participation, and class performance. This study sampled 377 undergraduates. Four exam scores and final semester grades were used to measure student performance. Students were also given a review score from LearnStar based on the speed and accuracy of their responses. They were given a survey on how beneficial they found the review sessions. The results were that the students enjoyed the LearnStar interactive review more than the traditional lecture reviews. They participated more and found them more interesting. This particular interactive review did not statistically improve student performance.

Research does show, however, that effective use of interactive technologies can have positive effects on learning outcomes. Hug et al (2005) found that an interactive learning technology in the form of a wearable programmable computer badge called a Thinking Tag can extend student thinking and help them create multiple representations of their understanding. The purpose of this research was to describe an initial study on the use of embedded learning technologies within a project-based curriculum enacted in an urban public school. The authors focus on the following questions: What characteristics of inquiry are seen when urban students and their teacher use learning technologies embedded within a project-based science unit? What levels of engagement are seen when urban students carry out technology supported inquiry? The authors believe that learning technologies can help students and teachers communicate, experience scientific phenomena, conduct investigations, and develop products. They used a web-based tool called Armetis to help students find support and reliable information on the Internet and Thinking Tags, which were wearable programmable computer badges. The authors found 
in their study of an $8^{\text {th }}$ grade science class of 33 students that both the Thinking Tag activity and the Artemis computer program allowed students to make strong, meaningful connections to their own lives. Their findings suggest that students can ask meaningful and worthwhile questions and have discussions about the scientific concepts aided by the learning technology without first having command of technical and scientific terms. Their research showed that interactive learning technology that promoted active learning had positive effects on student learning.

Interactive technology can be a powerful learning enhancement tool when used effectively by instructors is illustrated in a study. Schrand (2008) . The author created an interactive computer screen for a science class in which 26 elements could be moved around fluidly and rearranged at will. He challenged students to arrange these elements in groups and discuss how and why items were placed where they were. He found that students showed a higher level of engagement in class activities when this interactive technology was used and that the students communicated and shared more knowledge in a more spontaneous and authentic way than they had in any other active-learning exercise. He concluded that for effective use of computer technology in the classroom interactivity and highly visible public displays are two characteristics well suited for active and collaborative student centered learning.

In summary, information technologies can be powerful learning enhancement tools when used effectively by instructions. Schrand (2008) noted that many instructors use computers and other learning technologies just to present materials that might 
otherwise be presented in books or via lecture. In contrast, new technologies can be much more effectively used to build structures for active forms of student learning. The studies reported above illustrate just a few of the ways that interactive technologies can increase student engagement and learning.

\section{Clickers}

Clickers have the potential to increase active student participation, student performance, and class attendance. Beatty et al. (2008) found that students and instructors who have used clickers are mainly positive and enthusiastic about their effects on the classroom, and many researchers and educators believe they have potential to improve student learning. In her review of current literature and best practice, Caldwell (2007) found that the clicker is a powerful and flexible tool for teaching. She believes they can be incorporated into any course as a way to increase interaction between the teacher and students or as a teaching style that uses active learning. Caldwell finds that although more research needs to be done on clickers' effectiveness, research published so far shows that use of clickers has been able to enhance student's active learning, participation, and enjoyment of classes.

Stowell and Nelson (2007) compared clickers to standard lecture, hand-raising, and response card methods of student feedback in a simulated introductory psychology class. The purpose of their study was to examine whether the use of clickers in an undergraduate setting would result in greater learning, participation, honesty of student feedback, and more positive academic emotions than other methods of student responding. The researchers created four groups in an undergraduate psychology class in 
which participants were rewarded one hour of credit of a required four hours of research participation for the course. The four groups were: a standard lecture group $(n=34)$, a hand-raising review question group $(\mathrm{n}=35)$, a response card review question group $(\mathrm{n}=$ $36)$, and a clicker review question group $(n=35)$. The students attended two 30-minute introductory level psychology lectures. Throughout the lectures participation was recorded and the students were given a 10-item content quiz at the end of lecture. Scattered throughout the lecture were seven review questions that were used to determine honesty of student feedback for all the groups except the standard lecture group. At the beginning, during, and after the lecture students completed the Academic Emotions Questionnaire (AEQ) to measure their emotions over time in an academic setting. The results showed that participation was highest in the clicker group, followed by the response card, and finally the hand-raising group. On their analysis of learning gains, the researchers found no statistically significant differences on final quiz scores among any groups. On the AEQ the researchers found that the three groups with review questions were significantly less bored and had more pride than the standard lecture group. However, overall there were no statistically significant differences in the AEQ of the three review question groups. The researchers concluded that the benefits of using clickers are increases in participation and increases in student honesty during feedback. Learning gains were inconclusive due to the fact that the lectures were brief, the post lecture quiz may have been too difficult, and students had little motivation to do well since the score did not affect their grades. In the end, the researchers believe that clickers are a good way to get honest student feedback, boost participation, and increase student enjoyment. 
Martyn (2007) studied the learning outcomes in a college introductory computer information systems class. Her purpose was to find out whether clickers or active learning pedagogies are the cause of higher learning outcomes. She used class discussions as an active learning method for comparison with the use of clickers. She noted that both class discussions and clickers promote active learning, but the clicker incorporates two distinguishing features: they provide a mechanism for students to participate anonymously and they integrate a game approach that may engage more students than a traditional class discussion. She taught four sections of the same class, two in which she incorporated clickers $(n=45)$ and two in which she incorporated class discussions $(n=47)$. She gave a pretest to determine if there were any statistically significant differences between her groups at the beginning of the study. The clicker group averaged a 49.18 and the class discussion group averaged a 51.72 on the pretests showing no statistically significant differences. The same questions were used for both groups throughout the course. The only difference was that those involved in class discussions raised their hands, so their responses were not anonymous. She measured learning outcomes with the score on a comprehensive final exam at the end of the semester. Her final exam scores had a mean of 85.80 for the clicker group and 87.19 for the class discussion group, a difference that was not statistically significant. The researcher also gave students a survey to compare student perceptions of using clickers versus class discussions. The seven question, five point scale survey (1-strongly disagree to 5-strongly agree) found no statistically significant difference between the groups, however, the clicker group had a higher mean for every question. For example the question, "Participation with clickers (or class discussion) improved my grade in the 
course," scored a mean of 3.60 for the clicker group and a 3.20 for the class discussion group. The question, "Participation with clickers (or class discussion) increased my interaction with the instructor," scored a mean of 4.15 for the clicker group and a 3.62 for the class discussion group. The researcher concluded that although no statistically significant learning outcome results were found in this study, the perception survey found that students perceive value in the use of clickers and would like to see their continued use in future classes. The researcher also stated that she was surprised to find similar learning outcomes for each group and expected to see higher learning gains for the clicker group. She believes the reason for this was that the value of the active learning pedagogy was more important than the benefit of using clickers in this particular study. Her study ends with her suggestion that more research needs to be done to discover if clicker technology is better than using traditional active learning approaches.

Knight and Wood (2005) found increased learning gains when clickers were incorporated into a college biology course. The authors studied two biology classes, the first one (fall 2003) in which lecture was the dominant teaching method and the other (spring 2004) in which lecture time was decreased and replaced by active student participation and cooperative problem solving. The spring 2004 class used clickers to promote student participation and in-class assessment. The results were significantly higher learning gains in the interactive class that used clickers. Using normalized learning gains, which allowed for a valid comparison and averaging of learning gains for students with different pretest scores, showed compelling support for the interactive learning approach. A comparison of the two classes showed a $16 \%$ difference (46 to 62 ) in 
normalized learning gains, corresponding to a $43 \%$ improvement in performance by students in the interactive class compared to $21 \%$ in the traditional lecture. Learning gains of greater than $60 \%$ were achieved by substantially more students in the interactive class (43/70) than in the traditional lecture class (19/72). The authors did another study in the spring of 2005 to reproduce the learning gain comparisons. The results of the spring 2005 class showed similar learning gains to the spring 2004 class, which used the same interactive learning techniques and also incorporated clickers. This class had a normalized learning gain of 61 , which was $15 \%$ higher than the fall 2003 class and $1 \%$ lower than the fall 2004 class. The spring 2005 class showed a 35\% improvement in performance. Additionally in the spring 2005 class (34/69) achieved greater than $60 \%$ normalized learning gains. This study shows that the interactive learning techniques, which included using clickers, resulted in significant increases in learning gains. It is worth noting that the authors did use a variety of teaching methods: group work, discussions, addition of more participation-based activities, in addition to the clicker activities. This means no strategy in particular was controlled for in the interactive classes. The results nonetheless do show significant learning gains when the active learning methods were used with clickers.

The backbone of clicker effectiveness is based upon the quality and design of the questions that students are asked to answer. In recent years, Ian Beatty, has been exploring effective ways to ask questions with clickers. Beatty et al (2008) believes that good clicker questions should address a specific learning goal, skill, or reinforce a specific belief about learning. Beatty (2004) finds that questions can be used to 
effectively assess students' backgrounds, beliefs, and knowledge. They can also determine the source of students' misconceptions and confusion, make connections between ideas, and help apply new ideas in a different context. Beatty believes that peer instruction is a powerful method to use when using a Question-Driven Instruction approach that many clickers based activities can incorporate.

\section{Peer Instruction}

The literature reviewed in the previous sections demonstrates that positive learning gains and increases in student engagement result using certain interactive technologies in combination with active learning methods. The clicker is one such interactive technology that shows promise and potential to enhance students' learning and engagement in the classroom. Peer instruction is one active learning pedagogy that has shown to bring positive learning results to the classroom.

Crouch and Mazur showed the benefit of peer instruction in the classroom in their 2001 study. The authors conducted a 10-year study of peer instruction on introductory physics courses at Harvard University. The purpose of their study was to determine whether peer instruction was effective at improving students' understanding of the key concepts of physics. Peer instruction engages students by using activities during class that require them to explain the central content concepts to their fellow classmates. The authors believe that this method engages every student rather than just a few highly motivated students. Throughout the study, 5 different instructors taught the courses and were allowed to use peer instruction in their own style. This ensured that the results did 
not depend on a single instructor. Using the method of peer instruction for 10 years the authors found improved student learning. The resulting data showed a higher level of conceptual mastery and quantitative problem solving. The authors also found that students' success with the content improved over time the more familiar they became with the peer instruction methods. Crouch and Mazur do say that additional methods added to the courses increased the effects of peer instruction. One additional method they used was requiring students to pre-read content from a textbook at home before class to at least become familiar with the topics. Another method they implemented later on in their study was the addition of small discussion sections in which students could discuss misconceptions with a teaching assistant. In conclusion, peer instruction improved student test scores. Student performance on quantitative problems improved as well. In addition, students' attitudes and responses to peer instruction were generally positive.

Pollock (2006) found that peer learning in addition to other active learning methods have also resulted in higher learning gains than more traditional approaches such as a lecture. Pollock's purpose was to better understand the necessary and sufficient conditions for transferring, replicating, and sustaining successful learning environments. He studied peer instruction with personal response systems, tutorials with undergraduate learning assistants, and personalized computer assignments. He measured student success and attitude in multiple physics I and physics II courses by using pre-post content tests, attitude surveys, and common exam questions. In conclusion he found that interactive engagement was very important. When peer instruction and interactive engagement were used with the active learning methods of tutorials and personalized computer assignments 
he found the most significant positive outcomes in conceptual and attitudinal development. Indeed student-student interactions do have value in the classroom and lead to increased student learning.

Nichol and Boyle (2003) found that students prefer small group discussions to whole class discussions led by the teacher. Wood (2004) believes that the strength of peer instruction is the interactions that it fosters between students. Wood believes this to be true because students are better at clearing up misconceptions due to their similar ages, language, and common experiences.

In summary, current literature and research shows active learning to be an effective teaching strategy (Galichon and Friedman 1985, Narayan et al 1990, Zaremba and Dunn 2004). When active learning is coupled with interactive technology students show higher levels of engagement and understanding (Pemberton et al 2006, Hug et al 2005, Schrand 2008). Clickers are one form of interactive technology that have been shown to help boost student engagement, increase participation, and sometimes improve learning outcomes when they are used with effective teaching strategies (Martyn 2007, Caldwell 2007, Stowell and Nelson 2007, Beatty 2004, Beatty et al 2008, Knight and Wood 2005). A teaching strategy that has the potential to be effective when used with clickers is peer instruction. Peer instruction has been shown to increase student learning gains (Pollock 2006, Crouch and Mazur 2001, Nichol and Boyle 2003, Wood 2004). 
CHAPTER THREE: METHOD

\section{Overview}

This study will add to clicker research at the secondary school level by helping answer the question, "Are clickers that are used with peer instruction activities effective at improving student learning gains and increasing student engagement in secondary schools?"”

This mixed methods causal study examines the effectiveness of clickers and their use with peer instruction activities in a secondary school. Two classrooms were studied. Classroom A incorporated the use of clickers into peer instruction activities, while Classroom B did peer instruction activities without the use of the clickers. The course content, the amount of time spent on instruction, and the type of instruction were the same in each class. The independent variable in this study was the use of clickers and the dependent variables were the students' learning gains and the students' engagement. Controlled variables will be the course content and peer instruction. Qualitative and quantitative data were gathered to analyze the effectiveness of the clickers. Learning gains were measured quantitatively with pre and post assessment unit tests for each class. A learning objective scoring guide determined individual learning gains for each student. Student engagement was measured quantitatively with surveys and qualitatively with interviews to determine the students' enjoyment and perception of the clickers and their use in the classroom. Student engagement was additionally measured in two ways to determine active participation of the class as a whole. First, students took daily self- 
reflection surveys about the classroom discussions. These self-reflection surveys were not assessed for a student grade. They included a score (1-5) on how the student thought the discussions went and a score (1-5) on how they thought they participated. Student engagement was also measured was by examining how many and what type of questions students asked during a class period. Data was recorded on a chart in which the researcher tallied each student question and question type (yes/no, content related, other) during the discussion periods following each peer instruction coupled with clicker activity. This allowed the researcher to track class frequency of questions and types of questions.

Table 1

Summary of Methods, Treatment, and Measurements

\begin{tabular}{|l|}
\hline \multicolumn{1}{|c|}{ Classroom A: $\mathrm{O} 1 \rightarrow \mathrm{X} 1 \rightarrow \mathrm{O} 2, \mathrm{O} 3, \mathrm{O} 4, \mathrm{O} 5, \mathrm{O} 6$} \\
\hline \multicolumn{1}{|c|}{ Classroom B: $\mathrm{O} 1 \rightarrow \mathrm{X} 2 \rightarrow \mathrm{O} 2, \mathrm{O} 3, \mathrm{O} 4, \mathrm{O}$, O6 } \\
\hline Treatments: \\
\hline $\begin{array}{l}\text { X1: Clickers with peer instruction and peer instruction incorporated into classroom } \\
\text { activities }\end{array}$ \\
\hline X2: Peer instruction only incorporated into classroom activities \\
\hline Observations: \\
\hline O1: Pre-test \\
\hline O2: Daily self-reflective student survey \\
\hline $\begin{array}{l}\text { O3: Classroom engagement observations (tally of frequency and type of questions } \\
\text { asked during class discussions) }\end{array}$ \\
\hline O4: End of unit student perception survey \\
\hline O5: Student interviews \\
\hline O6: Post-test \\
\hline
\end{tabular}


Participants

Participants in this study were students at a midsize ( $\sim 1200$ students) high school in a Pacific Northwest suburb. Two science classrooms, Classroom A ( $\sim 15)$ and Classroom B ( $\sim 15)$, in which the researcher worked with a cooperating teacher, were the focus of the study. Classroom A was randomly chosen as the treatment group. Student interviews from Classroom A were also selected randomly. All students took the pre and post tests, completed the daily self-reflection surveys, and the end of the unit perception survey.

\section{Treatment}

The science content in this study was astronomy. The content in this unit was the same for both the treatment and control groups. All class activities, readings, and lessons were the same for both groups with the exception of the use of the clickers in the experimental group. There were no perceived differences between the two classes in this study. Both classes met on the same day one period after the other.

\section{Experimental Treatment}

The experimental treatment group, Classroom A, first took a pre test. This pre test gave each student a score on the unit's six learning objectives. Each lesson during the unit focused on these learning objectives. During the daily lessons the treatment group was presented with a number of questions (3-7), which they answered with the clickers, answering each question when it was presented. They would then see the class distribution of answers and would work with a partner in a peer instruction session. These 
peer instruction sessions ranged from 1 to 2 minutes. Discussions involved the content from the question. The students then re-answered the question with the clicker and the instructor would finally reveal the correct answer to the students. The students and instructor then had a class discussion on the content included in the question. During this discussion the instructor tallied the number and type of each question asked. At the end of each class period the instructor tallied all the questions and types of questions and record that class period's total. At the end of each class period, the students were given a selfreflection survey in which they were asked to give themselves a score of 1 (bad) to 5 (great) on how they thought the class discussions went that day and how they thought they participated. On the last day of the unit the students took a post-test. The content of the post-test was based off of the unit's learning objectives, but did not include any identical questions on the pre-test. By comparing the change in the pre-test and post-test scores the researcher was able to calculate a numerical learning gain for each student. Both the pre-test and the post-test used a scoring guide to determine the scores. Also on the final day of the unit the students were given a seven-question perception survey in which they ranked answers from 1 (completely disagree) to 5 (completely agree). They were also given the opportunity to include any comments about clickers and peer instruction that they had. Finally, four students were selected at random to participate in brief 5-minute interviews in which they were asked in more detail about the use of the clickers. Through these methods the researcher was able to measure student learning (pre-test and post-test scores) and student engagement (daily discussion question tallies, student self-reflection surveys, end of unit perception surveys, and interviews). 
Control Group

The control group, Classroom B, first took a pre-test. This pre-test gave each student a score on the unit's six learning objectives. Each lesson during the unit focused on these different learning objectives. During the daily lessons the treatment group was presented with a number of questions (3-7), which they answered on white boards with markers. The students answered each question when it was presented. They, however, would not see the class distribution of answers. They would then work with a partner in a peer instruction session. These peer instruction sessions ranged from 1 to 2 minutes. The students then re-answered the question and the instructor would finally reveal the correct answer to the students. The students and instructor then had a class discussion on the content mentioned in the question. During this period the instructor tallied the number and type of each question asked. At the end of each class period the instructor tallied all the questions and types of questions and record that class period's total. At the end of each class period, the students were given a self-reflection survey in which they were asked to give themselves a score of 1 (bad) to 5 (great) on how they thought the class discussions went that day and how they thought they participated. On the last day of the unit the students took a post-test. The content of the post-test was based off of the unit's learning objectives. By comparing the change in the pre-test and post-test scores the researcher was able to calculate a numerical learning gain for each student. Both the pretest and the post-test used a scoring guide to determine the scores. Also on the final day of the unit the students were given a seven-question perception survey in which they ranked answers from 1 (completely disagree) to 5 (completely agree). They were also given the opportunity to include any comments about the clickers and peer instruction 
that they had. Through these treatments the researcher was able to measure student learning (pre-test and post-test scores) and student engagement (daily discussion question tallies, student self-reflection surveys, and end of unit perception surveys).

\section{Instruments}

Two different types of instruments were used in this study, those that measured student learning and those that measured student engagement. Both are discussed in detail below.

\section{Measuring Student Learning}

Pre-test. The same pre-test was administered to Classroom A and Classroom B. Its purpose was to give the researcher an understanding of the students' content knowledge prior to instruction. The pre-test was based on six learning objectives, which were based on state and national science standards on astronomy. The pre-test questions were asked in an open format so that students were forced to reveal knowledge as opposed to accidentally guess correctly on multiple choice or matching questions. The pre-test is inculded in the appendix.

Post-test. The same post-test was administered to Classroom A and Classroom B. Its purpose was to give the researcher an understanding of the students' content knowledge after instruction. The post-test was based on the same six learning objectives as the pre-test. The post-test questions were a mixture of multiple choice, matching, word bank fill-ins, and diagram identifications. The post-test is included in the appendix. 
Pre-test/post-test scoring guide. In order to score the pre- and post-tests the researcher used a scoring guide in which particular criteria needed to be met in order to receive points. Each learning objective was assessed on a scale of 0 (lowest) to 2 (highest). By matching student responses on the pre-test and post-test with the scoring guide, each student was given a pre-test score and a post-test score. The difference in these scores is referred to as the student learning gain score. The pre-test/post-test scoring guide is included in the appendix.

\section{Measuring Student Engagement}

Daily Self-Reflective Surveys. Every day during the unit students were asked to rate class discussions on a scale from 1 (bad) to 5 (great) and their participation from 1 (bad) to 5 (great) for that class period. These surveys were used to determine whether or not students felt more engaged in class discussions and class participation when they were using the clickers. These surveys are included in the appendix.

Perception Surveys. At the end of the unit students completed a survey asking about their perceptions of the clickers with peer instruction or peer instruction without the use of the clickers. A similar survey was used by Martyn (2007) to measure students' perceptions of clickers in her undergraduate introductory computer information systems course. A similar version of Martyn's survey was used because of its face reliability and validity. The researcher used this seven-question survey and had students rate statements based on a 1 (strongly disagree) to 5 (strongly agree) scale. Two versions were given to compare the two classes at the end of the unit. Classroom A's survey asked about clickers 
and peer instruction while Classroom B's asked only about peer instruction. These surveys were used to see the perceived differences in engagement caused by the clickers. Each class' survey is included in the appendix.

Interviews. Student interviews contained 10 general questions about clickers and peer instruction. Four interviews were completed with students chosen at random from Classroom A. The themes that these interviews focused on were student attitudes and feelings towards the clickers and the way the clickers were used (peer instruction). The reason for this was to get a more in depth look at how the students perceived the clickers and whether or not the students believed the clickers and the associated learning strategy contributed to their engagement and learning. Upon completing the student interviews, the researcher identified common themes based on student responses to questions about the clickers. The themes that appeared in the students' responses during the interviews were student enjoyment in the use of the clickers, student self-perception in participation and learning, student preference for specific clicker strategies, and student desire for future use of clickers. These student responses were synthesized and grouped together for the analysis of this data.The interview questions are included in the appendix.

\section{Procedure}

This study occurred in the spring term of 2011 at a midsize ( $\sim 1200$ students) high school in a Pacific Northwest suburb. At the start of the unit the researcher administered a content based pre-test on an astronomy unit to both Classroom A, the treatment group, and Classroom B, the control group. The treatment throughout the unit occurred during 
the daily lessons. During each daily lesson, 3-7 questions were asked to each class. These questions were spread throughout the class period and covered the main concepts of the day, which were based off of the unit's learning objectives. The creation and implementation of the questions was based on the Question Cycle (figure 1). The Question Cycle is a core component of Question-Driven Instruction developed by used by Beatty et al. (2004) as a way to design effective questions for classroom response system teaching. When a "clicker" question was asked by the researcher, everyone in Classroom A responded with his or her clicker. Students in Classroom B were given small whiteboards and markers on which to record their answers. The students then worked in pairs and attempted to explain why they chose the answer they did to their partner. Students discussed the answers in their peer groups for 1-2 minutes and attempted to teach and convince each other that their answer was correct. The researcher then asked the students the same question again and students were able to re-answer the question taking into account the discussion they had with their partner. The correct answer was then revealed and the researcher invited the class to openly discuss the question and its answer. During this discussion the researcher tallied the number and type of questions for each classroom. At the end of each class period students were asked to give the class discussions and their participation for that day a score from 1 (bad) to 5 (great). At the end of the unit the researcher gave students a content-based post-test, based on the six learning objectives for the unit. Students were also given the perception survey as described in the instrument section above. Four students were selected randomly to answer interview questions based on their experiences using the clickers and peer instruction activities. 


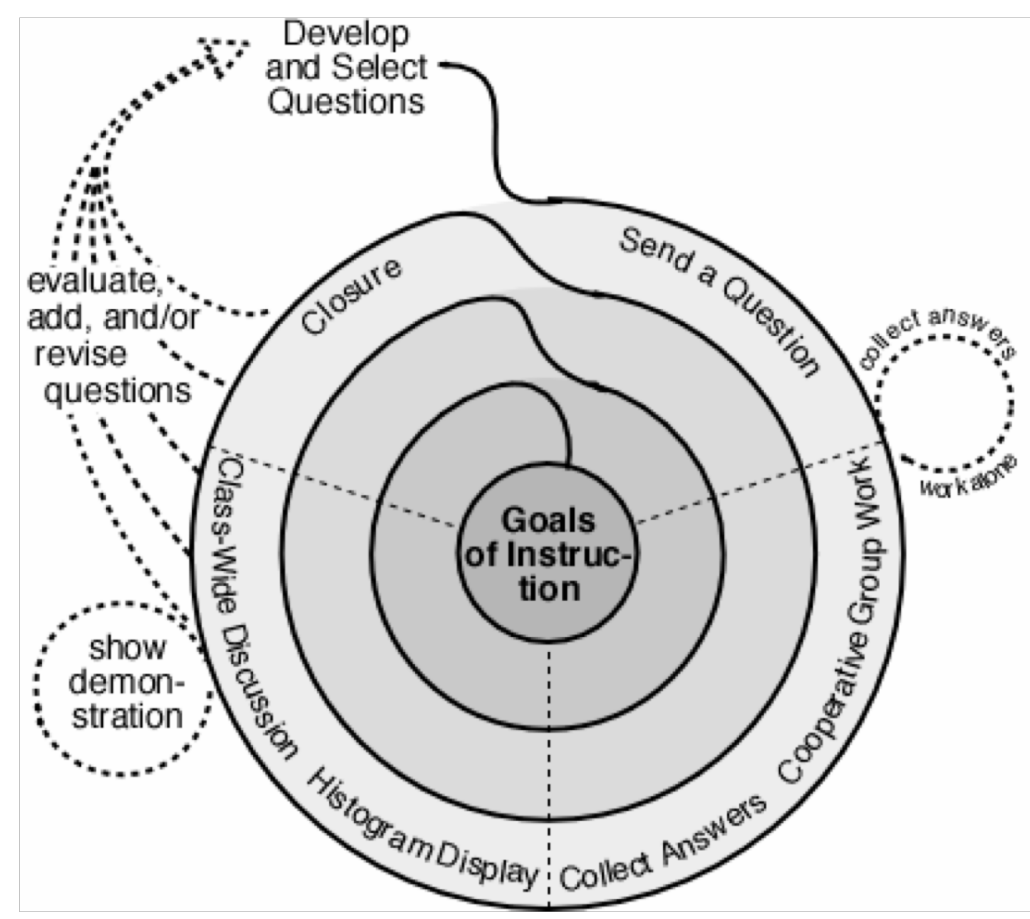

Figure 1. The Question Cycle, Beatty et al (2004). 
CHAPTER FOUR: RESULTS

\author{
Learning Gains
}

Learning gains were determined from pre-test and post-test data. Tests were scored using the scoring guide, to determine pre- and post-test values. The differences in these values are the learning gains. The pre-test and post-test were based on six unit learning objectives. For each learning objective a student could earn a 0 (lowest knowledge) to a 2 (highest knowledge). Therefore, the maximum score one could receive on either the pre- or post-test was a 12 and the minimum was a 0 . The following data tables and charts summarize the data. 
Table 2

Classroom $A^{1}$ Learning Gains

\begin{tabular}{|l|l|l|l|}
\hline Students & Pre-test & Post-test & Learning Gains \\
\hline 1 & 4 & 11 & 7 \\
\hline 2 & 2 & 10 & 8 \\
\hline 3 & 0 & 9 & 9 \\
\hline 4 & 3 & 11 & 8 \\
\hline 5 & 1 & 11 & 10 \\
\hline 6 & 4 & 11 & 7 \\
\hline 7 & 4 & 10 & 6 \\
\hline 8 & 0 & 6 & 6 \\
\hline 9 & 1 & 10 & 9 \\
\hline 10 & 5 & 12 & 7 \\
\hline 11 & 1 & 7 & 6 \\
\hline 12 & 1 & 8 & 7 \\
\hline 13 & 1 & 6 & 5 \\
\hline 14 & 2 & 12 & 10 \\
\hline Mean & 2.07 & 9.57 & 7.50 \\
\hline St Dev & 1.64 & 2.06 & 1.56 \\
\hline
\end{tabular}

${ }^{1}$ One student from Classroom A was absent and had never taken the post-test, hence the $\mathrm{n} \sim 14$. 
Table 3

Classroom B Learning Gains

\begin{tabular}{|l|l|l|l|}
\hline Student & Pre-test & Post-test & Learning Gains \\
\hline 1 & 4 & 12 & 8 \\
\hline 2 & 1 & 12 & 11 \\
\hline 3 & 0 & 11 & 11 \\
\hline 4 & 2 & 11 & 9 \\
\hline 5 & 1 & 10 & 9 \\
\hline 6 & 1 & 4 & 3 \\
\hline 7 & 0 & 9 & 9 \\
\hline 8 & 1 & 10 & 9 \\
\hline 9 & 1 & 10 & 9 \\
\hline 10 & 1 & 12 & 11 \\
\hline 11 & 2 & 5 & 3 \\
\hline 12 & 1 & 10 & 9 \\
\hline 13 & 3 & 10 & 7 \\
\hline 14 & 1 & 11 & 10 \\
\hline 15 & 1 & 7 & 6 \\
\hline Mean & 1.33 & 9.60 & 8.27 \\
\hline St Dev & 1.05 & 2.44 & 2.55 \\
\hline
\end{tabular}

Table 4

Statistical Tests for Learning Gains of Classroom A and Classroom B

\begin{tabular}{|l|l|}
\hline F Test & 0.084 \\
\hline T Test & 0.341 \\
\hline
\end{tabular}

Results of the f-test: F-test shows equal variances since $0.08>0.05$.

Results of the t-test: The p-value associated with the t-test is not small $(>0.05)$, so there is not enough evidence to reject the null hypothesis. Therefore, there is evidence that the means are not different. 


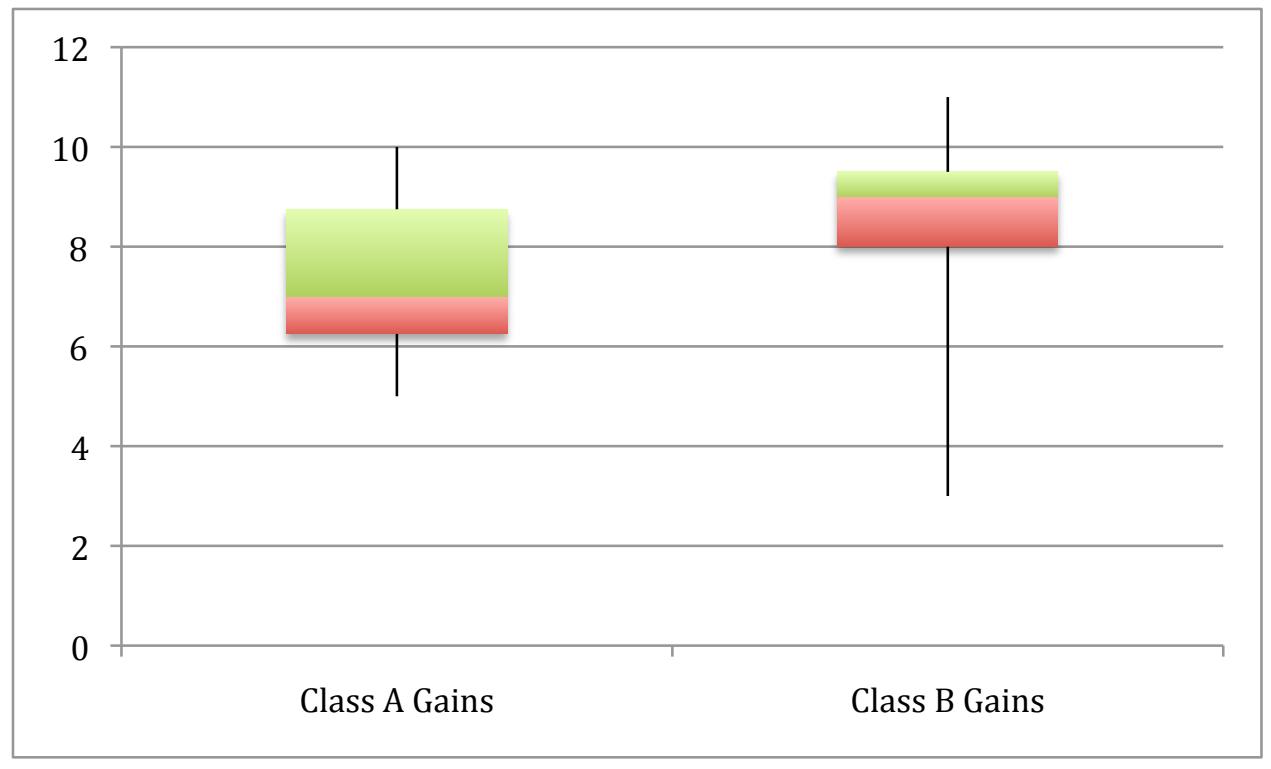

Figure 2. Box and Whisker Plot of Learning Gains

In summary, the data for learning gains shows no statistically significant learning gains for either class.

\section{Student Engagement - Quantitative}

\section{Daily Questions Tally}

Multiple instruments were used to determine student engagement quantitatively. First, daily tallies were taken by the researcher to determine the differences in the quantity and type of questions asked by students during classroom discussions. Classroom discussions occurred during every lesson after a "clicker" question was asked and the Question Cycle process was completed. The researcher tallied the number and type of questions asked during these discussions. During a given lesson the number of “clicker" questions varied from 3 to 7 . In total, 29 questions were asked throughout the unit. All questions asked by both Classroom A and Classroom B were content based. 
Table 5

Number of Questions Asked

\begin{tabular}{|l|l|l|}
\hline Class Day & Classroom A & Classroom B \\
\hline April 22 & 1 & 3 \\
\hline April 26 & 2 & 2 \\
\hline May 2 & 2 & 3 \\
\hline May 4 & 7 & 4 \\
\hline May 6 & 5 & 6 \\
\hline May 10 & 1 & 3 \\
\hline May 12 & 2 & 1 \\
\hline Sum & 20 & 22 \\
\hline Mean & 2.86 & 3.14 \\
\hline St Dev & 2.27 & 1.57 \\
\hline Min & 1 & 1 \\
\hline $1^{\text {st }}$ Quartile & 1.5 & 2.5 \\
\hline Median & 2 & 3 \\
\hline $3^{\text {rd }}$ Quartile & 3.5 & 3.5 \\
\hline Max & 7 & 6 \\
\hline
\end{tabular}

Table 6

Statistical Tests for Number of Questions Asked

\begin{tabular}{|l|l|}
\hline F Test & 0.395 \\
\hline T Test & 0.394 \\
\hline
\end{tabular}

Results of the f-test: F-test shows equal variances since $0.395>0.05$.

Results of the t-test: The p-value associated with the t-test is not small $(>0.05)$, so there is not enough evidence to reject the null hypothesis. Therefore, there is evidence that the means are not different. 


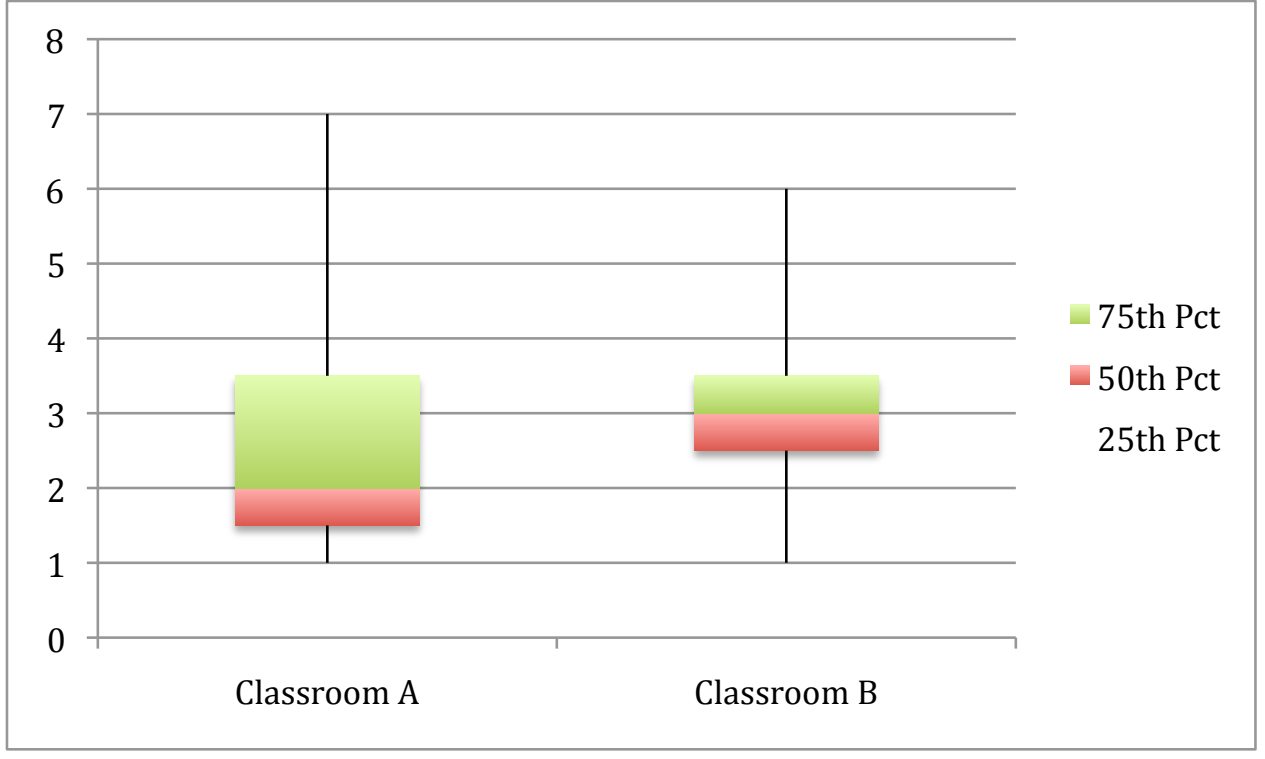

Figure 3. Box and Whisker Plot of Number of Questions Asked 
Self Reflection Surveys

At the end of every class period students took a survey on a scale of 1 (bad) to 5 (great) ranking that class' discussions and their own participation for the day. Both Classroom A and Classroom B did this every day of the unit for a total of 7 times. Days in which a student was absent were not counted and were left blank in the tables.

Table 7

Daily Classroom Discussions Classroom A

\begin{tabular}{|l|l|l|l|l|l|l|l|}
\hline Student & April 22 & April 26 & May 2 & May 4 & May 6 & May 10 & May 12 \\
\hline 1 & & 5 & 4 & 5 & 4 & 5 & 5 \\
\hline 2 & 4 & 4 & 4 & 5 & 5 & 5 & 5 \\
\hline 3 & 4 & 4 & & 4 & 5 & 5 & 5 \\
\hline 4 & & & 5 & 5 & & 5 & 5 \\
\hline 5 & 4 & 5 & 5 & 5 & 5 & 5 & 5 \\
\hline 6 & 5 & 4 & 5 & 5 & 4 & 5 & 5 \\
\hline 7 & 4 & 5 & 5 & & & & 5 \\
\hline 8 & 4.5 & 4 & 5 & & 3 & & \\
\hline 9 & & 5 & 5 & & 4 & 5 & \\
\hline 10 & 4 & 4 & 5 & 4 & 5 & 3 & 5 \\
\hline 11 & 4 & & 5 & & & 5 & \\
\hline 12 & 4 & 5 & 5 & 5 & 5 & 5 & 5 \\
\hline 13 & 5 & 5 & 5 & 5 & 5 & 5 & 5 \\
\hline 14 & 3.5 & 4 & & 4 & 4 & & 4 \\
\hline 15 & 4 & 4 & 4 & 4 & 5 & 5 & 5 \\
\hline Mean & 4.17 & 4.46 & 4.77 & 4.64 & 4.50 & 4.83 & 4.92 \\
\hline
\end{tabular}


Table 8

Statistical Analysis of Daily Classroom Discussions Classroom A

\begin{tabular}{|l|l|}
\hline Sum & 392.00 \\
\hline Mean & 4.61 \\
\hline St Dev & 0.54 \\
\hline Min & 3.00 \\
\hline 1st Quartile & 4.00 \\
\hline Median & 5.00 \\
\hline 3rd Quartile & 5.00 \\
\hline Max & 5.00 \\
\hline
\end{tabular}

Table 9

Daily Classroom Discussions Classroom B

\begin{tabular}{|l|l|l|l|l|l|l|l|}
\hline Student & April 22 & April 26 & May 2 & May 4 & May 6 & May 10 & May 12 \\
\hline 1 & 5 & 4 & 5 & 5 & 3 & 2 & 3 \\
\hline 2 & 4 & 5 & 4 & 5 & 5 & 5 & 5 \\
\hline 3 & 4 & 4 & 3 & 5 & 4 & 4 & 4 \\
\hline 4 & 3 & 5 & 4 & 5 & 5 & 2 & 5 \\
\hline 5 & 5 & 5 & 5 & 5 & 5 & 5 & \\
\hline 6 & 4 & 3 & & 4 & 3 & 4 & 4 \\
\hline 7 & 5 & 5 & 4 & & 4 & 4 & 5 \\
\hline 8 & & 4 & 4 & 4 & 4 & 4 & 4 \\
\hline 9 & 4 & 5 & 5 & 5 & 5 & 5 & 5 \\
\hline 10 & 5 & 5 & 4 & 5 & 5 & 5 & 5 \\
\hline 11 & & 4 & 4 & 4 & 4 & & 5 \\
\hline 12 & 3.5 & 3.5 & 3.5 & 3.5 & 4 & 4 & 4 \\
\hline 13 & 4 & 3.5 & 4 & 4 & 4 & 4 & 4 \\
\hline 14 & 4 & & 4 & 5 & 4 & 3 & \\
\hline 15 & 5 & 5 & 5 & 5 & 5 & 5 & 5 \\
\hline Mean & 4.27 & 4.36 & 4.18 & 4.61 & 4.27 & 4.00 & 4.46 \\
\hline
\end{tabular}


Table 10

Statistical Analysis of Daily Classroom Discussions Classroom B

\begin{tabular}{|l|l|}
\hline Sum & 417.50 \\
\hline Mean & 4.30 \\
\hline St Dev & 0.72 \\
\hline Min & 2.00 \\
\hline 1st Quartile & 4.00 \\
\hline Median & 4.00 \\
\hline 3rd Quartile & 5.00 \\
\hline Max & 5.00 \\
\hline
\end{tabular}

Table 11

Statistical Tests for Daily Discussions for Classroom A and Classroom B

\begin{tabular}{|l|l|}
\hline F Test & 0.0072 \\
\hline T Test & 0.0006 \\
\hline
\end{tabular}

Results of the f-test: F-test shows unequal variances since $0.0072<0.01$

Results of the t-test: The p-value associated with the t-test is small $(<0.01)$, therefore there is evidence that the means are significantly different at the significance level reported by the p-value. 


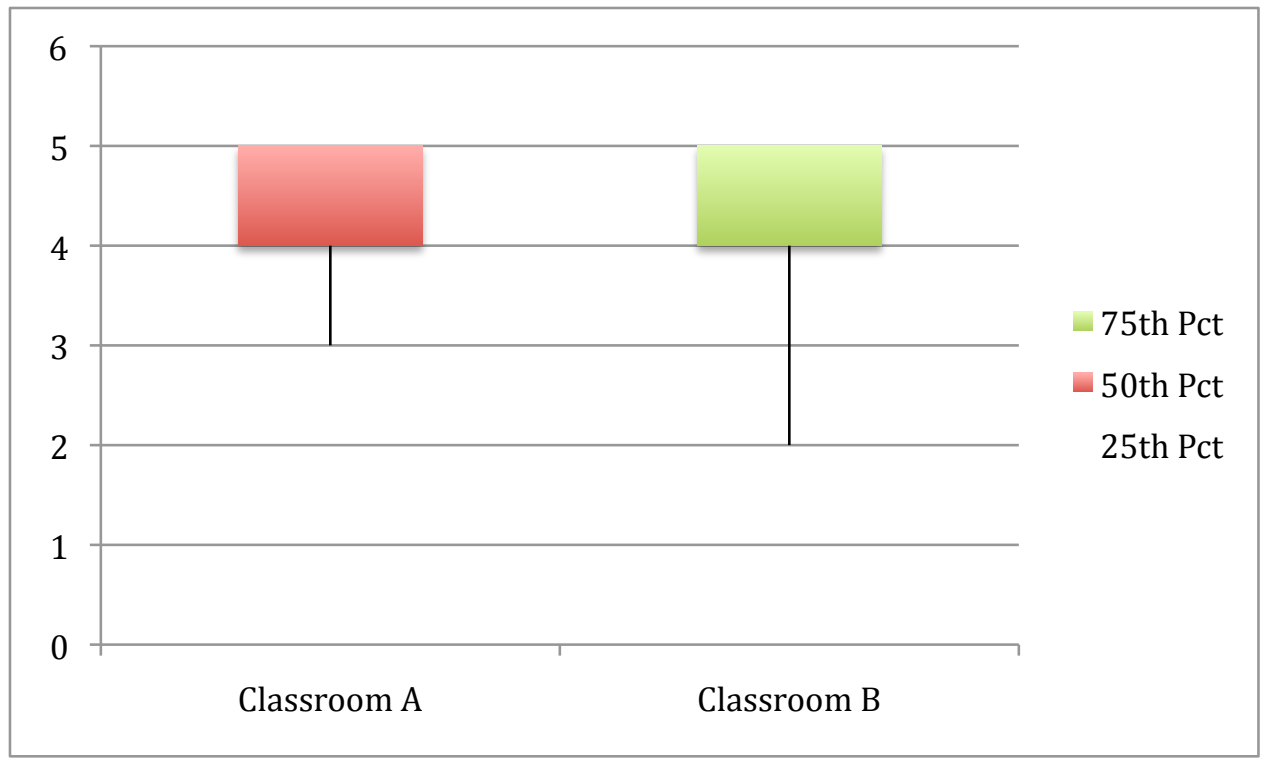

Figure 4. Box and Whisker Plot of Daily Discussions

Table 12

Daily Self Reflection Participation Classroom A

\begin{tabular}{|l|l|l|l|l|l|l|l|}
\hline Student & April 22 & April 26 & May 2 & May 4 & May 6 & May 10 & May 12 \\
\hline 1 & & 5 & 3 & 5 & 4 & 5 & 5 \\
\hline 2 & 5 & 4 & 3 & 3 & 5 & 5 & 5 \\
\hline 3 & 4 & 4 & & 4 & 5 & 5 & 5 \\
\hline 4 & & & 5 & 5 & 1 & 5 & 5 \\
\hline 5 & 4 & 4 & 3 & 5 & 5 & 5 & 5 \\
\hline 6 & 5 & 4 & 5 & 5 & 5 & 5 & 5 \\
\hline 7 & 4 & 5 & 4 & & & & 4 \\
\hline 8 & 5 & 5 & 5 & & 5 & & \\
\hline 9 & & 5 & 4 & & 4 & 5 & \\
\hline 10 & 5 & 5 & 5 & 5 & 5 & 5 & 5 \\
\hline 11 & 5 & & 5 & & & 5 & \\
\hline 12 & 4 & 5 & 5 & 5 & 5 & 5 & 5 \\
\hline 13 & 5 & 5 & 5 & 5 & 5 & 5 & 5 \\
\hline 14 & 4 & 4 & & 4 & 4 & & 4 \\
\hline 15 & 5 & 3 & 5 & 4 & 5 & 5 & 5 \\
\hline Mean & 4.58 & 4.46 & 4.38 & 4.55 & 4.46 & 5.00 & 4.83 \\
\hline
\end{tabular}


Table 13

Statistical Analysis of Daily Self Reflection Participation Classroom A

\begin{tabular}{|l|l|}
\hline Sum & 396.00 \\
\hline Mean & 4.60 \\
\hline St Dev & 0.71 \\
\hline Min & 1.00 \\
\hline 1st Quartile & 4.00 \\
\hline Median & 5.00 \\
\hline 3rd Quartile & 5.00 \\
\hline Max & 5.00 \\
\hline
\end{tabular}

Table 14

Daily Self Reflection Participation Classroom B

\begin{tabular}{|l|l|l|l|l|l|l|l|}
\hline Student & April 22 & April 26 & May 2 & May 4 & May 6 & May 10 & May 12 \\
\hline 1 & 5 & 4 & 5 & 5 & 3 & 1 & 5 \\
\hline 2 & 4 & 5 & 4 & 5 & 5 & 4 & 4 \\
\hline 3 & 5 & 4 & 5 & 5 & 4 & 5 & 5 \\
\hline 4 & 5 & 5 & 3 & 5 & 5 & 5 & 5 \\
\hline 5 & 5 & 5 & 5 & 3 & 4 & 5 & \\
\hline 6 & 4 & 4 & & 4 & 3 & 4 & 4 \\
\hline 7 & 4 & 5 & 3 & & 5 & 3 & 5 \\
\hline 8 & & 4 & 4 & 5 & 5 & 5 & 5 \\
\hline 9 & 5 & 5 & 5 & 5 & 5 & 5 & 5 \\
\hline 10 & 5 & 5 & 5 & 5 & 5 & 5 & 5 \\
\hline 11 & & 5 & 4 & 5 & 5 & & 4 \\
\hline 12 & 4 & 4 & 4 & 4 & 4 & 4 & 4 \\
\hline 13 & 5 & 4 & 4 & 5 & 4 & 4 & 4 \\
\hline 14 & 3 & & 4 & 3 & 5 & 2 & \\
\hline 15 & 5 & 5 & 5 & 5 & 5 & 5 & 5 \\
\hline Mean & 4.54 & 4.57 & 4.29 & 4.57 & 4.47 & 4.07 & 4.62 \\
\hline
\end{tabular}


Table 15

Statistical Analysis of Daily Self Reflection Participation Classroom A

\begin{tabular}{|l|l|}
\hline Sum & 431.00 \\
\hline Mean & 4.44 \\
\hline St Dev & 0.78 \\
\hline Min & 1.00 \\
\hline 1st Quartile & 4.00 \\
\hline Median & 5.00 \\
\hline 3rd Quartile & 5.00 \\
\hline Max & 5.00 \\
\hline
\end{tabular}

Table 16

Statistical Tests for Daily Self Reflection Participation for Classroom A and Classroom B

\begin{tabular}{|l|l|}
\hline F Test & 0.38 \\
\hline T Test & 0.07 \\
\hline
\end{tabular}

Results of the f-test: F-test shows equal variances since $0.38>0.01$

Results of the t-test: The p-value associated with the t-test is not small $(>0.01)$, so there is not enough evidence to reject the null hypothesis. Therefore, there is evidence that the means are not different. 


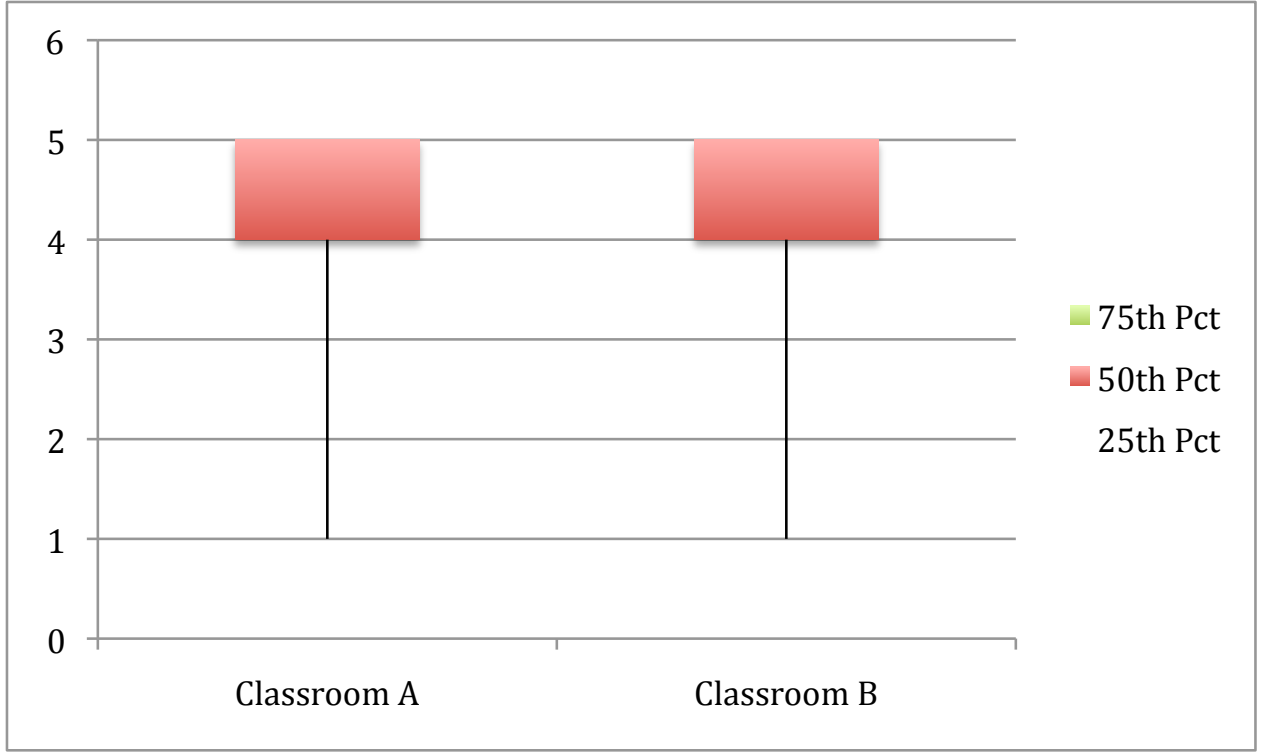

Figure 5. Box and Whisker Plot of Daily Self Reflection Participation 
End of Unit Perception Survey

At the end of the unit both Classroom A and Classroom B took a seven question perception survey. Classroom A's questions involved the use of the clickers with peer instruction, while Classroom B's questions involved only peer instruction. Fourteen students from each class took the survey, 1 was absent from each class. All survey data is ranked on a scale 1 (Disagree Strongly) to 5 (Agree Strongly).

A - 1: Participation with clickers and peer instruction improved my grade in the unit.

B - 1: Participation with peer instruction improved my grade in the unit.

Table 17

End of Unit Survey Question 1 for Classroom A and Classroom B

\begin{tabular}{|l|l|l|}
\hline Student & Classroom A & Classroom B \\
\hline 1 & 3 & 3 \\
\hline 2 & 4 & 5 \\
\hline 3 & 5 & 4 \\
\hline 4 & 5 & 4 \\
\hline 5 & 4 & 3 \\
\hline 6 & 2 & 5 \\
\hline 7 & 5 & 4.5 \\
\hline 8 & 3 & 5 \\
\hline 9 & 4 & 5 \\
\hline 10 & 3 & 4 \\
\hline 11 & 4 & 4.5 \\
\hline 12 & 5 & 4 \\
\hline 13 & 3 & 5 \\
\hline 14 & 4 & 4 \\
\hline Mean & 3.86 & 4.29 \\
\hline St Dev & 0.95 & 0.70 \\
\hline Min & 2 & 3 \\
\hline 1st Quartile & 3 & 4 \\
\hline Median & 4 & 4.25 \\
\hline 3rd Quartile & 4.75 & 5 \\
\hline Max & 5 & 5 \\
\hline & &
\end{tabular}


Table 18

Statistical Tests for End of Unit Survey Question 1 for Classroom A and Classroom B

\begin{tabular}{|c|c|}
\hline F Test & 0.28 \\
\hline T Test & 0.09 \\
\hline
\end{tabular}

Results of the f-test: F-test shows equal variances since $0.283>0.05$

Results of the t-test: The p-value associated with the t-test is not small $(>0.05)$, so there is not enough evidence to reject the null hypothesis. Therefore, there is evidence that the means are not different.

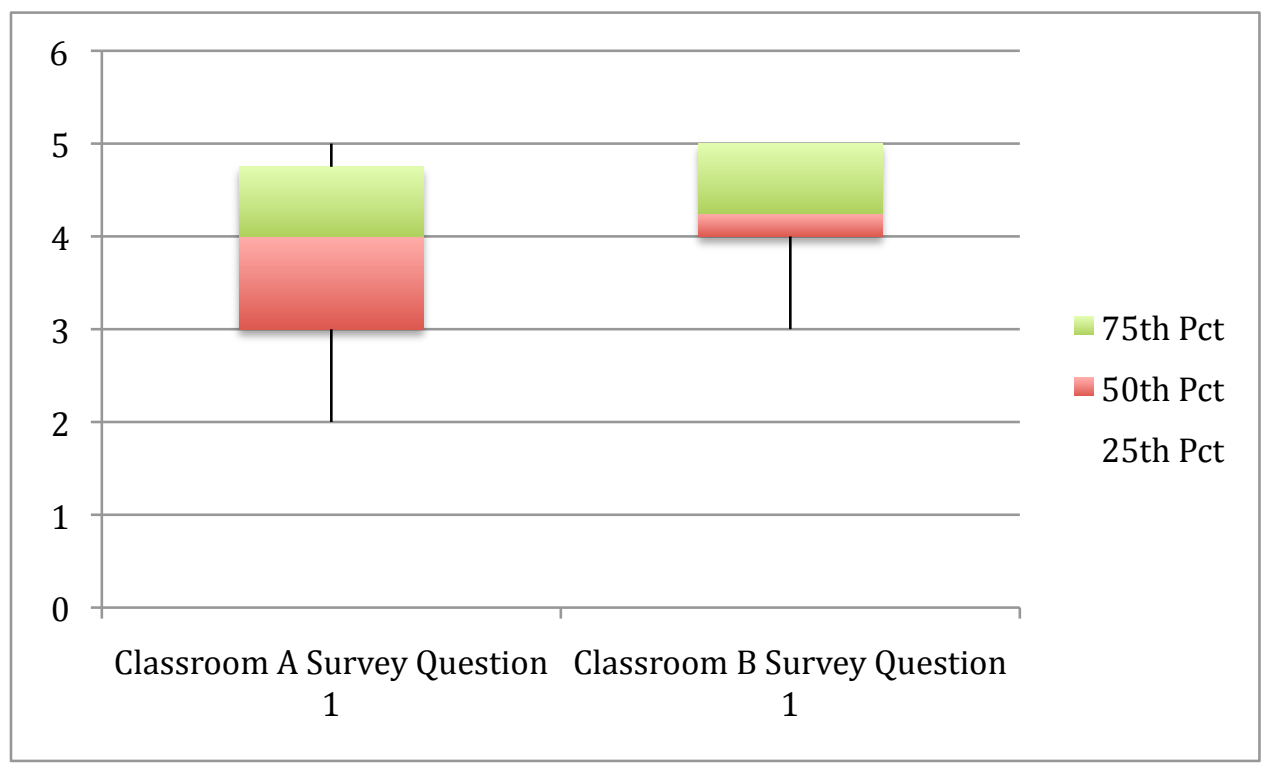

Figure 6. Box and Whisker Plot of Survey Question 1 
A - 2: Participation with clickers and peer instruction improved my understanding of the subject content.

B - 2: Participation with peer instruction improved my understanding of the subject content.

Table 19

End of Unit Survey Question 2 for Classroom A and Classroom B

\begin{tabular}{|l|l|l|}
\hline Student & Classroom A & Classroom B \\
\hline 1 & 4 & 3 \\
\hline 2 & 5 & 5 \\
\hline 3 & 5 & 5 \\
\hline 4 & 5 & 5 \\
\hline 5 & 5 & 4 \\
\hline 6 & 4 & 4 \\
\hline 7 & 4 & 4 \\
\hline 8 & 4 & 5 \\
\hline 9 & 3 & 5 \\
\hline 10 & 4 & 5 \\
\hline 11 & 5 & 4 \\
\hline 12 & 5 & 5 \\
\hline 13 & 4 & 4 \\
\hline 14 & 5 & 5 \\
\hline Mean & 4.43 & 4.50 \\
\hline St Dev & 0.65 & 0.65 \\
\hline Min & 3 & 3 \\
\hline 1 st Quartile & 4 & 4 \\
\hline Median & 4.5 & 5 \\
\hline 3rd Quartile & 5 & 5 \\
\hline Max & 5 & 5 \\
\hline
\end{tabular}

Table 20

Statistical Tests for End of Unit Survey Question 2 for Classroom A and Classroom B

\begin{tabular}{|l|l|}
\hline F Test & 0.98 \\
\hline T Test & 0.39 \\
\hline
\end{tabular}


Results of the f-test: F-test shows equal variances since $0.982>0.05$

Results of the t-test: The p-value associated with the t-test is not small $(>0.05)$, so there is not enough evidence to reject the null hypothesis. Therefore, there is evidence that the means are not different.

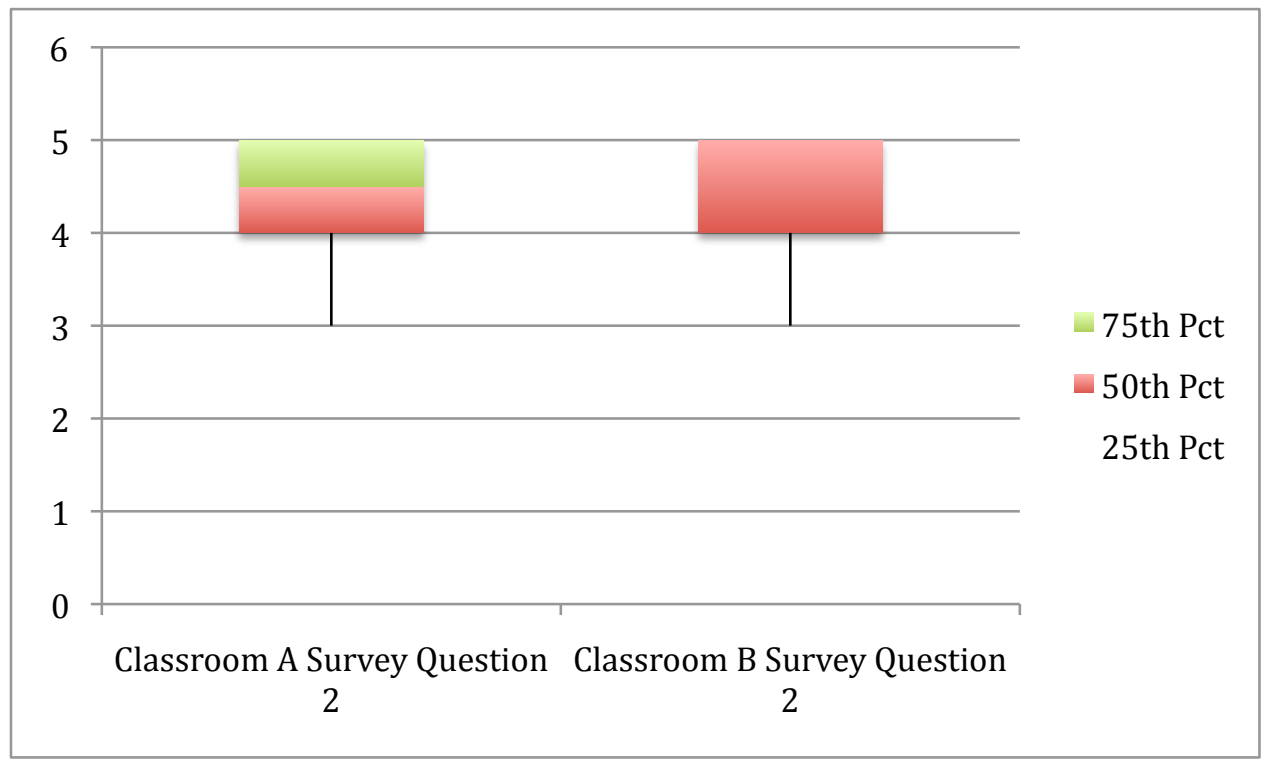

Figure 7. Box and Whisker Plot of Survey Question 2 
A - 3: Participation with clickers and peer instruction increased my feeling of participation in this class.

B - 3: Participation with peer instruction increased my feeling of participation in this class.

Table 21

End of Unit Survey Question 3 for Classroom A and Classroom B

\begin{tabular}{|l|l|l|}
\hline Student & Classroom A & Classroom B \\
\hline 1 & 5 & 4 \\
\hline 2 & 5 & 4 \\
\hline 3 & 5 & 5 \\
\hline 4 & 5 & 5 \\
\hline 5 & 4 & 3 \\
\hline 6 & 4 & 4 \\
\hline 7 & 4 & 4 \\
\hline 8 & 5 & 4 \\
\hline 9 & 4 & 5 \\
\hline 10 & 4 & 4 \\
\hline 11 & 5 & 3.5 \\
\hline 12 & 5 & 4 \\
\hline 13 & 4 & 5 \\
\hline 14 & 5 & 5 \\
\hline Mean & 4.57 & 4.25 \\
\hline St Dev & 0.51 & 0.64 \\
\hline Min & 4 & 3 \\
\hline 1 st Quartile & 4 & 4 \\
\hline Median & 5 & 4 \\
\hline 3rd Quartile & 5 & 5 \\
\hline Max & 5 & 5 \\
\hline & & \\
\hline
\end{tabular}

Table 22

Statistical Tests for End of Unit Survey Question 3 for Classroom A and Classroom B

\begin{tabular}{|c|c|}
\hline F Test & 0.43 \\
\hline T Test & 0.08 \\
\hline
\end{tabular}


Results of the f-test: F-test shows equal variances since $0.428>0.05$

Results of the t-test: The p-value associated with the t-test is not small $(>0.05)$, so there is not enough evidence to reject the null hypothesis. Therefore, there is evidence that the means are not different.

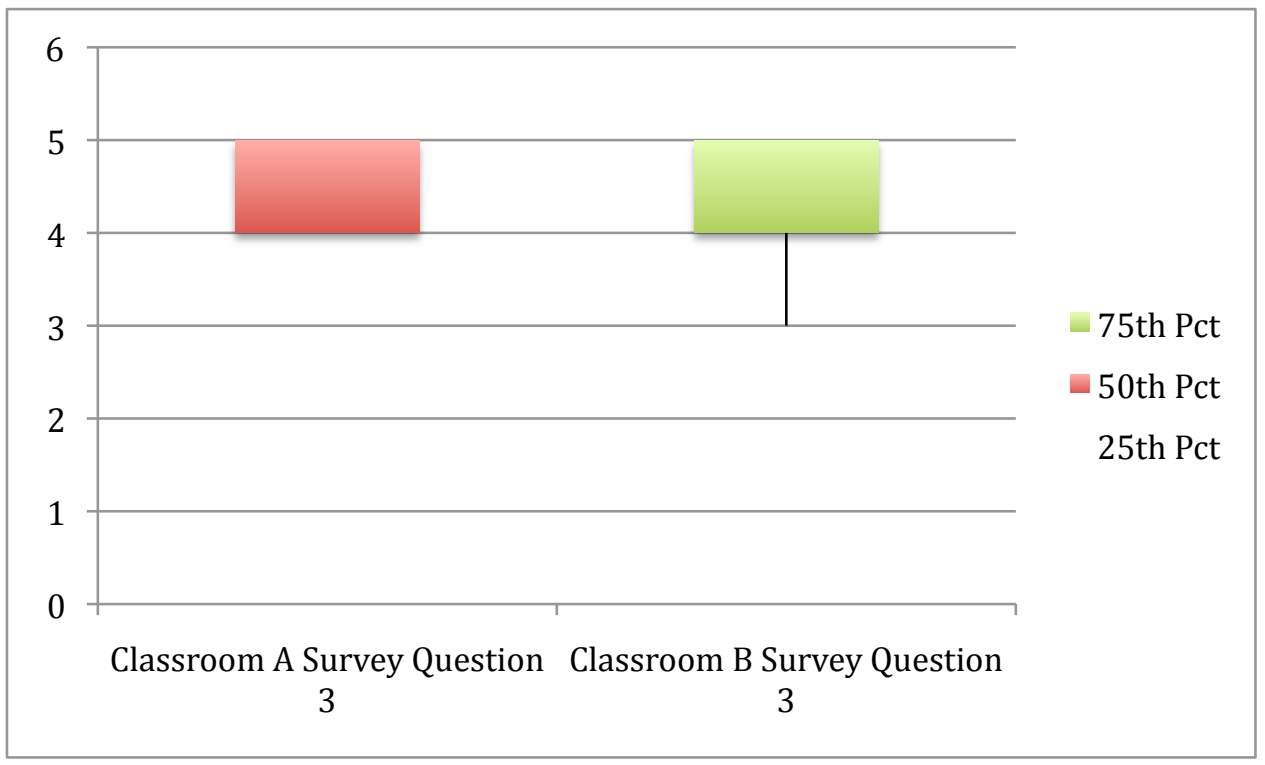

Figure 8. Box and Whisker Plot of Survey Question 3 
A - 4: Participation with clickers and peer instruction increased my interaction with the instructor.

B - 4: Participation with peer instruction increased my interaction with the instructor.

Table 23

End of Unit Survey Question 4 for Classroom A and Classroom B

\begin{tabular}{|l|l|l|}
\hline Student & Classroom A & Classroom B \\
\hline 1 & 4 & 4 \\
\hline 2 & 5 & 4 \\
\hline 3 & 5 & 5 \\
\hline 4 & 5 & 4 \\
\hline 5 & 3 & 4 \\
\hline 6 & 4 & 5 \\
\hline 7 & 5 & 4 \\
\hline 8 & 3 & 4 \\
\hline 9 & 5 & 4.5 \\
\hline 10 & 4 & 4 \\
\hline 11 & 5 & 4 \\
\hline 12 & 5 & 5 \\
\hline 13 & 4 & 3 \\
\hline 14 & 4 & 5 \\
\hline Mean & 4.36 & 4.25 \\
\hline St Dev & 0.74 & 0.58 \\
\hline Min & 3 & 3 \\
\hline 1 st Quartile & 4 & 4 \\
\hline Median & 4.5 & 4 \\
\hline 3rd Quartile & 5 & 4.875 \\
\hline Max & 5 & 5 \\
\hline & & \\
\hline
\end{tabular}

Table 24

Statistical Tests for End of Unit Survey Question 4 for Classroom A and Classroom B

\begin{tabular}{|c|c|}
\hline F Test & 0.38 \\
\hline T Test & 0.34 \\
\hline
\end{tabular}


Results of the f-test: F-test shows equal variances since $0.379>0.05$

Results of the t-test: The p-value associated with the t-test is not small $(>0.05)$, so there is not enough evidence to reject the null hypothesis. Therefore, there is evidence that the means are not different.

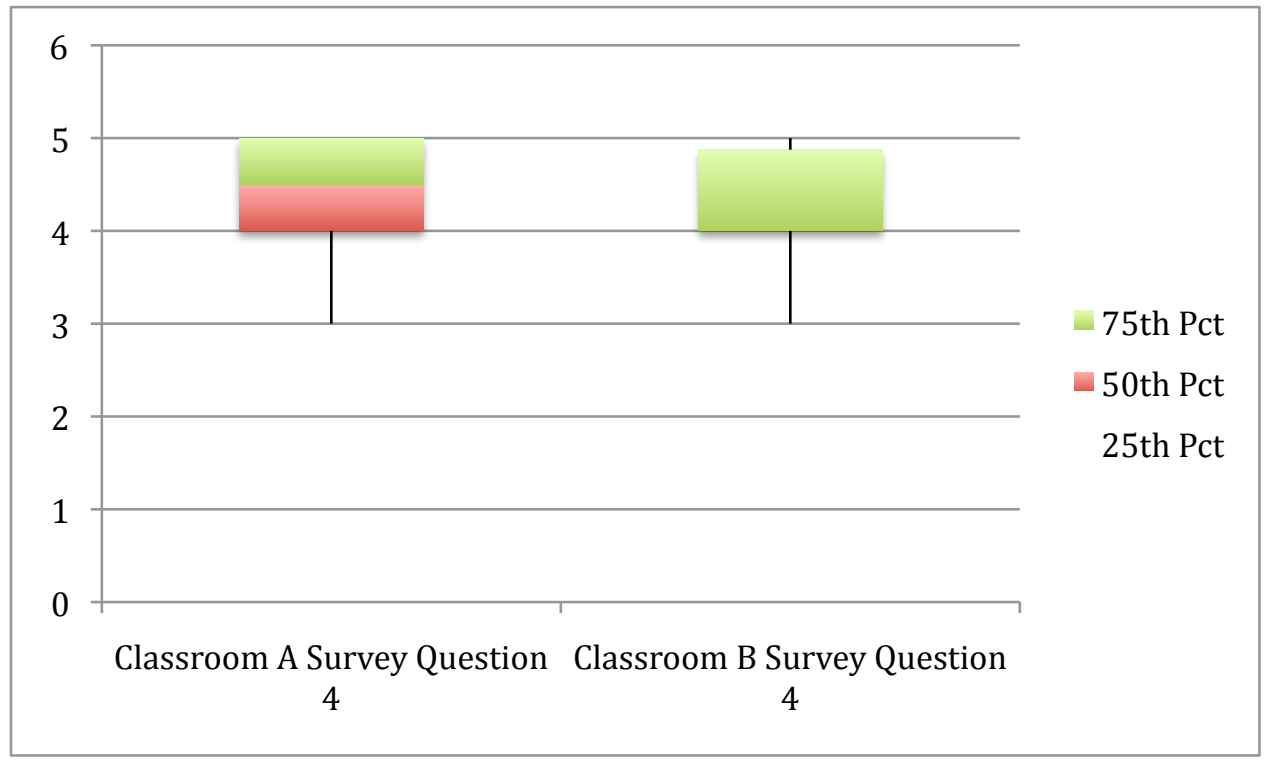

Figure 9. Box and Whisker Plot of Survey Question 4 
A - 5: Participation with clickers and peer instruction increased my interaction with other students.

B - 5: Participation with peer instruction increased my interaction with other students.

Table 25

End of Unit Survey Question 5 for Classroom A and Classroom B

\begin{tabular}{|l|l|l|}
\hline Student & Classroom A & Classroom B \\
\hline 1 & 5 & 3 \\
\hline 2 & 5 & 4 \\
\hline 3 & 5 & 4 \\
\hline 4 & 5 & 5 \\
\hline 5 & 4 & 4 \\
\hline 6 & 3 & 4 \\
\hline 7 & 5 & 4 \\
\hline 8 & 3 & 4 \\
\hline 9 & 5 & 5 \\
\hline 10 & 3 & 5 \\
\hline 11 & 4 & 3.5 \\
\hline 12 & 5 & 4 \\
\hline 13 & 3 & 5 \\
\hline 14 & 5 & 5 \\
\hline Mean & 4.29 & 4.25 \\
\hline St Dev & 0.91 & 0.64 \\
\hline Min & 3 & 3 \\
\hline 1 st Quartile & 3.25 & 4 \\
\hline Median & 5 & 4 \\
\hline 3 rd Quartile & 5 & 5 \\
\hline Max & 5 & 5 \\
\hline & & \\
\hline & 5 & 5 \\
\hline
\end{tabular}

Table 26

Statistical Tests for End of Unit Survey Question 5 for Classroom A and Classroom B

\begin{tabular}{|c|c|}
\hline F Test & 0.22 \\
\hline T Test & 0.45 \\
\hline
\end{tabular}


Results of the f-test: F-test shows equal variances since $0.218>0.05$

Results of the t-test: The p-value associated with the t-test is not small $(>0.05)$, so there is not enough evidence to reject the null hypothesis. Therefore, there is evidence that the means are not different.

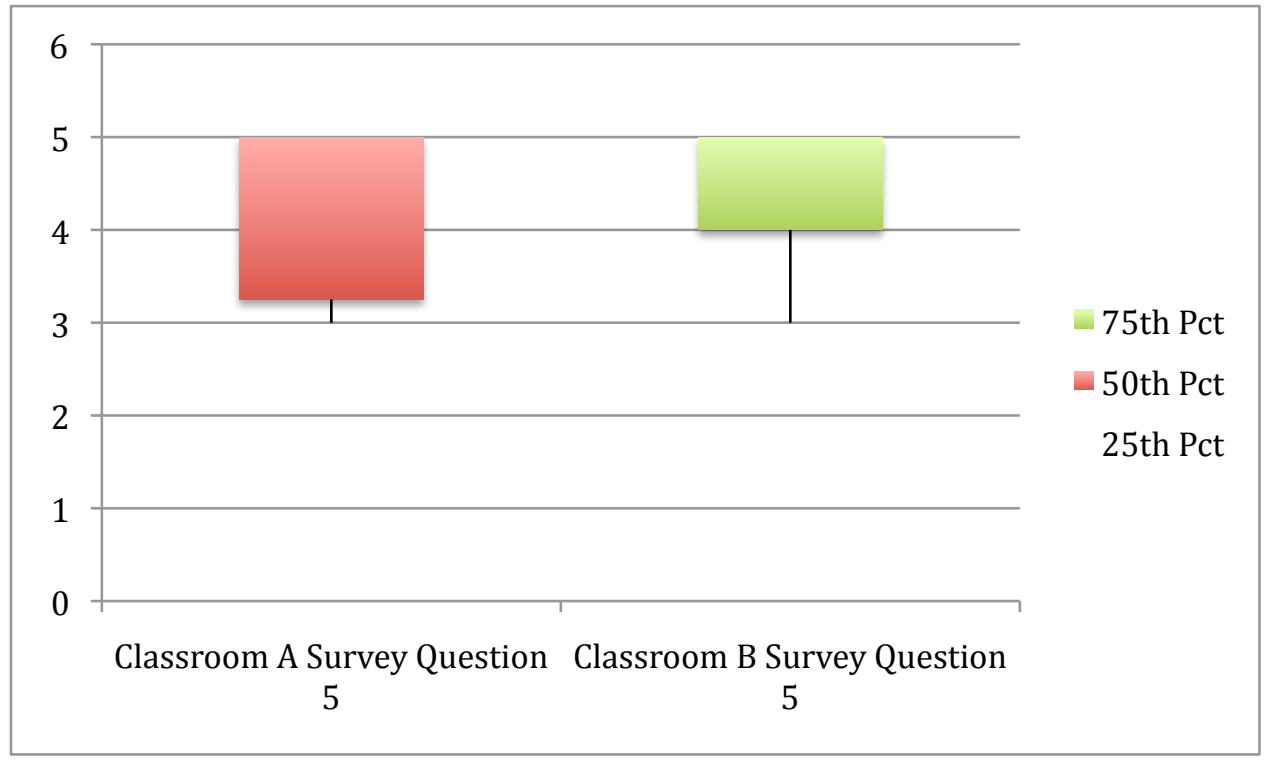

Figure 10. Box and Whisker Plot of Survey Question 5 
A - 6: I enjoyed activities that used clickers and peer instruction.

B - 6: I enjoyed activities that used peer instruction.

Table 27

End of Unit Survey Question 6 for Classroom A and Classroom B

\begin{tabular}{|l|l|l|}
\hline Student & Classroom A & Classroom B \\
\hline 1 & 5 & 5 \\
\hline 2 & 5 & 5 \\
\hline 3 & 5 & 5 \\
\hline 4 & 5 & 4 \\
\hline 5 & 5 & 3 \\
\hline 6 & 5 & 5 \\
\hline 7 & 5 & 4 \\
\hline 8 & 4 & 4 \\
\hline 9 & 4 & 5 \\
\hline 10 & 5 & 4 \\
\hline 11 & 5 & 4 \\
\hline 12 & 5 & 5 \\
\hline 13 & 3 & 4 \\
\hline 14 & 5 & 5 \\
\hline Mean & 4.71 & 4.43 \\
\hline St Dev & 0.61 & 0.65 \\
\hline Min & 3 & 3 \\
\hline 1 st Quartile & 5 & 4 \\
\hline Median & 5 & 4.5 \\
\hline 3rd Quartile & 5 & 5 \\
\hline Max & 5 & 5 \\
\hline & & \\
\hline
\end{tabular}

Table 28

Statistical Tests for End of Unit Survey Question 6 for Classroom A and Classroom B

\begin{tabular}{|c|c|}
\hline F Test & 0.84 \\
\hline T Test & 0.12 \\
\hline
\end{tabular}


Results of the f-test: F-test shows equal variances since $0.844>0.05$

Results of the t-test: The p-value associated with the t-test is not small $(>0.05)$, so there is not enough evidence to reject the null hypothesis. Therefore, there is evidence that the means are not different.

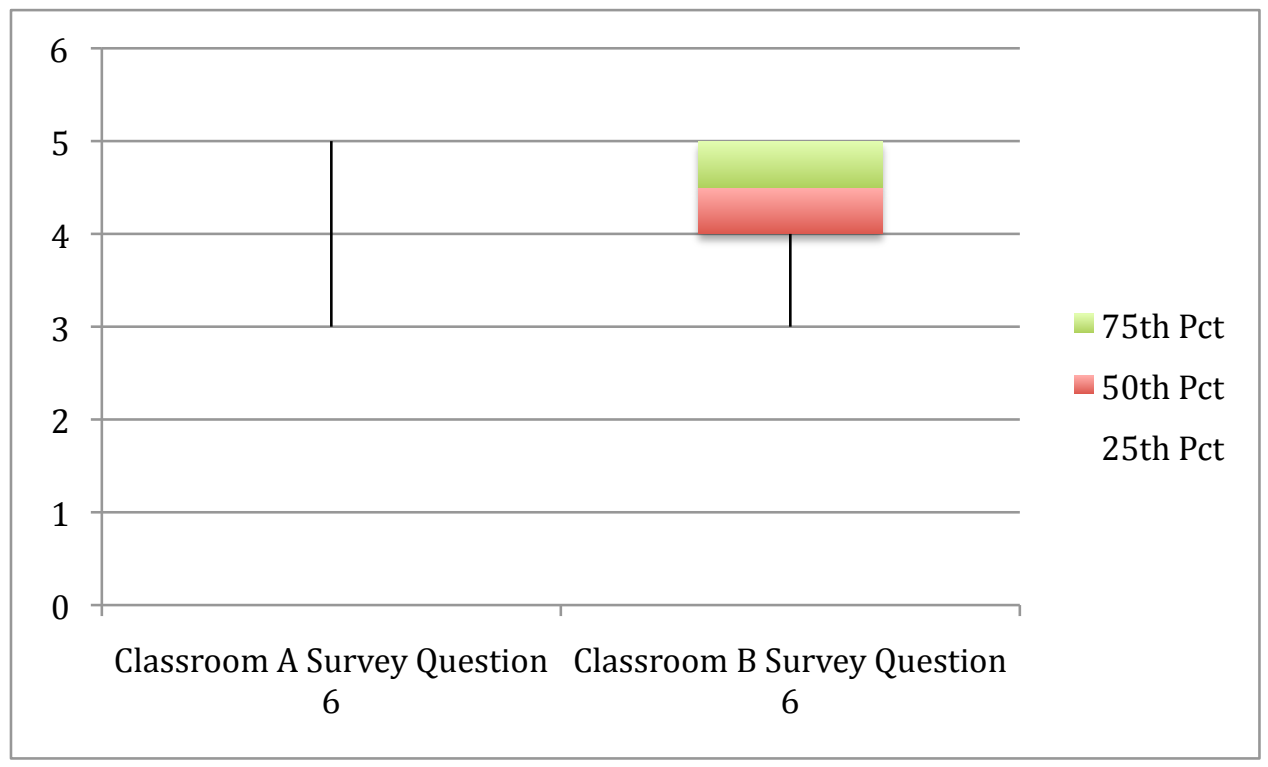

Figure 11. Box and Whisker Plot of Survey Question 6 
A - 7: I would recommend using clickers and peer instruction again in this class.

B - 7: I would recommend using peer instruction again in this class.

Table 29

End of Unit Survey Question 7 for Classroom A and Classroom B

\begin{tabular}{|l|l|l|}
\hline Student & Classroom A & Classroom B \\
\hline 1 & 5 & 5 \\
\hline 2 & 5 & 5 \\
\hline 3 & 5 & 5 \\
\hline 4 & 5 & 5 \\
\hline 5 & 4 & 4 \\
\hline 6 & 5 & 4 \\
\hline 7 & 5 & 4 \\
\hline 8 & 4 & 5 \\
\hline 9 & 4 & 5 \\
\hline 10 & 5 & 3 \\
\hline 11 & 5 & 4 \\
\hline 12 & 5 & 5 \\
\hline 13 & 4 & 5 \\
\hline 14 & 5 & 5 \\
\hline Mean & 4.71 & 4.57 \\
\hline St Dev & 0.47 & 0.65 \\
\hline Min & 4 & 3 \\
\hline 1 st Quartile & 4.25 & 4 \\
\hline Median & 5 & 5 \\
\hline 3rd Quartile & 5 & 5 \\
\hline Max & 5 & 5 \\
\hline & &
\end{tabular}

Table 30

Statistical Tests for End of Unit Survey Question 7 for Classroom A and Classroom B

\begin{tabular}{|c|c|}
\hline F Test & 0.26 \\
\hline T Test & 0.25 \\
\hline
\end{tabular}


F-test shows equal variances since $0.260>0.05$

Results of the t-test: The p-value associated with the t-test is not small $(>0.05)$, so there is not enough evidence to reject the null hypothesis. Therefore, there is evidence that the means are not different.

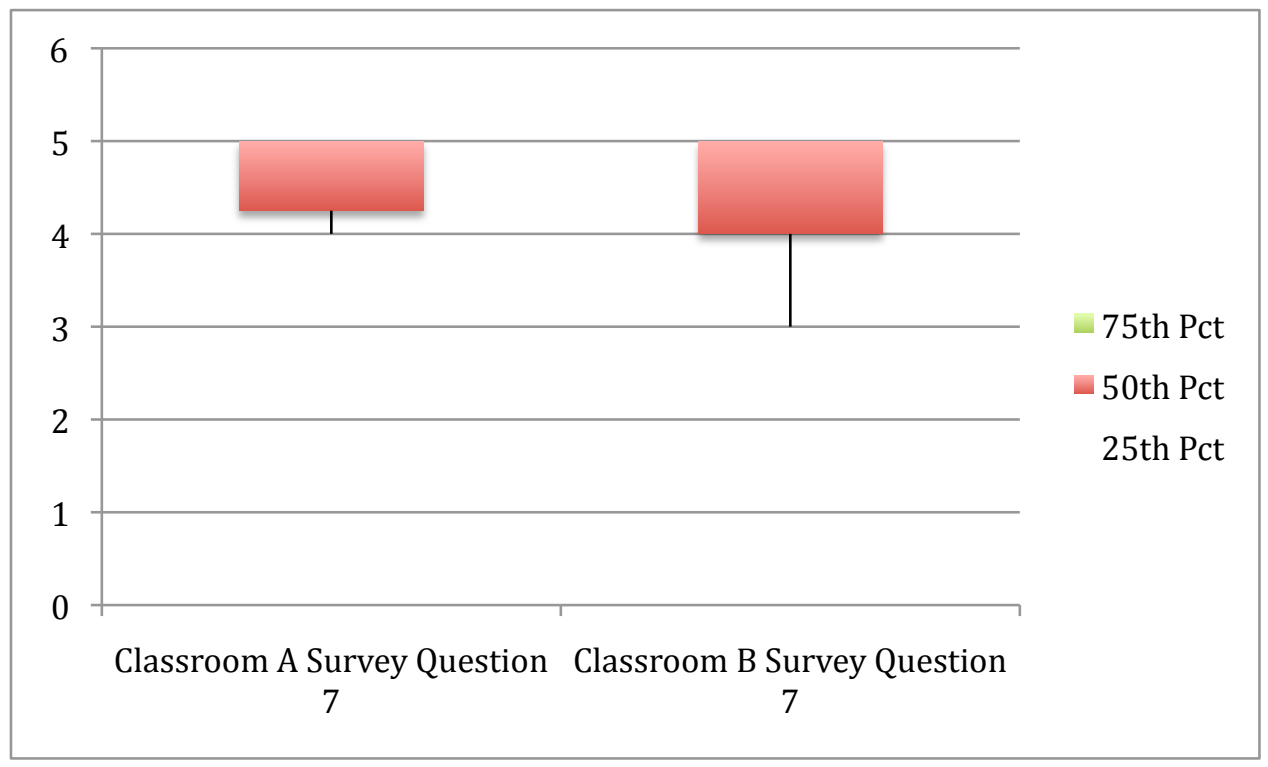

Figure 12. Box and Whisker Plot of Survey Question 7 
Student Engagement - Qualitative

\section{End of Unit Perception Survey Comments}

Only three comments were left in the comments section of the perception survey. They were all left by Classroom A. Classroom B left 0 comments.

\section{Classroom A}

"The clickers are cool, and so are you!"

"They were enjoyable!"

"I think by using the clickers I was more prepared for the test!"

\section{Classroom B}

No comments were written

\section{Student Interviews}

Four students were selected randomly to take part in interviews about the unit and about the clickers at the end of the unit. Each interview lasted about 4 to 5 minutes. One theme present in all the interviews was that the students liked using the clickers. The students all responded positively to questions about the use of the clickers during peer instruction activities. The students all felt that they participated more and learned more because of the clickers. They liked the way clickers were incorporated in to the class. They said they would not change the way they were used, but did state they would like 
them to be used more and in additional classes. The following quotations demonstrate these ideas and themes.

Interview 1: Thought the clickers were beneficial to the class and helped participation. Enjoyed the kinesthetic aspect of the clickers.

Interview 2: Thought the clickers helped the student learn more and participate more. Thought the peer instruction activities were useful.

"Yeah (the clickers) were pretty great. It helped answer the question better."

Interview 3: Enjoyed using the clickers. Enjoyed the anonymity of the clickers and the idea that everyone was equal in answering questions with the clickers. Would like to use the clickers more often and in other classes.

Interview 4: Thought the clickers were enjoyable. Liked using the clickers especially with peer instruction. Liked the interactive nature of the clickers with peer instruction. "I liked when we used the clickers." "Yeah because we actually got to do something instead of just sitting there." 
CHAPTER FIVE: DISCUSSION

The purpose of this research study was to answer the question, "Are clickers that are used with peer instruction activities effective at improving student learning gains and increasing student engagement in secondary schools?" The researcher's hypothesis was that the use of the clickers would result in higher learning gains and more student engagement.

\author{
Interpret Findings
}

\title{
Learning Gains
}

The data in this research suggests that the students that used the clickers made no statistically significant learning gains over the students who did not use them. All students were subject to the same lessons, activities, and class structure. All content was taught the same to both classes with the exception of Classroom A's use of the clickers.

\section{Engagement}

The data in this study suggests there were mixed results in student engagement. The majority of the quantitative data suggests that there was no statistical difference in engagement in either class.

The one exception to that is the daily discussions self-reflection survey. The daily discussions were on average statistically better in the classroom that used the clickers. Since the students thought the discussions were better this leads the researcher to believe 
they were slightly more engaged in the class content. However, as far as class participation in the self-reflection survey there was no statistical difference in the two classes. The end of unit student perception surveys all showed no statistical advantage to the clickers as far as perceived benefits in learning gains, engagement, and participation.

Some of the qualitative data suggests that the students did benefit from and enjoyed using the clickers. Although limited in number the comment section of the survey included comments such as, "The clickers are cool," "They were enjoyable," and "I think by using the clickers I was more prepared for the test." This leads the researcher to believe that the clickers were indeed enjoyed by some of the students. The student interviews also brought out the notion that the students were engaged by, enjoyed, and benefited from the clickers. All students interviewed thought that the clickers helped them learn more and helped them participate more. They all thought that using the clickers with peer instruction was useful. All of them thought that the clickers were used in a good way in the class. All of them also said that they liked technology in science classes.

In interview 3, when asked about activities in the unit that the student liked the student responded with "Doing the clickers." The following dialog gives evidence for the student's engagement with the clickers while using peer instruction:

Researcher: Ok. So you liked using the clickers. Do you think you learned more by using the clickers? 
Interviewee 3: Yeah. Because you are talking about it more. So if someone would switch to a different answer then they could tell us why it was different.

Researcher: Ok. Do you feel like in class you were able to participate more using the clickers?

Interviewee 3: Yeah cause everyone is equal.

This student gave the impression that the clickers were a useful tool to use in the class. The student felt safer in participating and felt a sense of equity among all the students. The student also liked the idea that being wrong wasn't necessarily a bad thing as they could see others in the class were wrong as well and then had time to correct their answer.

Interviewee 4 gave similar impressions. The following dialog suggests the student's enjoyment and perceived benefit in engagement due to the use of the clickers.

Researcher: As far as activities or things we did in class every day, what things did you like the most or dislike?

Interviewee 4: I liked when we used the clickers.

Researcher: You liked that?

Interviewee 4: Yeah.

Researcher: Ok what did you like about them? 
Interviewee 4: Cause you could ask the people around us to help us understand. They would help me change my mind so if I didn't know it I would know it by the end.

Researcher: Do you think that it was more engaging to be in class and sitting there in lecture and being able to participate with those...(interrupted) Interviewee 4: Yeah because we actually got to do something instead of just sitting there.

This last response is of particular interest because it clearly shows the student's engagement was influenced by the use of the clickers. The student even goes as far to interrupt mid question to point out that using the clickers was "doing something" during a lecture as opposed to "just sitting there." This statement is evidence of increased engagement by this student due to the use of the clickers.

The general impression that the interviews give is that the students enjoyed the clickers. They felt that the clickers were a benefit to their learning, engagement, and participation. 
Limitations

The purpose of this study was to examine the effectiveness of clickers and their use with peer instruction activities in a secondary school. This purpose was achieved by attempting to provide an answer to the question, "Are clickers that are used with peer instruction activities effective at improving student learning gains and increasing student engagement in secondary schools?" This question was answered in this study, but with multiple limitations.

First, the sample sizes of the two groups was small at $\mathrm{n} \sim 15$. Since the research was done in $9^{\text {th }}$ grade science classes the participants needed to have a parent or guardian sign a consent form. Both classes contained 25 students, but only 15 in each class had their parents sign the consent form. For this reason the statistical analysis in all of the categories of the surveys is not the complete story of the class. Additionally, the tallies of questions and types of questions during class discussion only includes data from students whose parents signed consent. There were an additional 10 students in each class that were asking questions and participating in discussions.

Another limitation in this study was the pre-test, post-test, and their scoring guide. These were created by the researcher and were based off of national and state science standards. However, these tests and the scoring guide were subjective to the researcher's desired learning outcomes. 
A third limitation of this study was student absences. Classroom A had a larger number of student absences throughout the unit, which resulted in less class time. These students all took the same pre- and post-tests though, so the absent students were at a disadvantage due to the lack of instruction.

A fourth limitation of this study was its length and content. The treatment and use of the clickers occurred for only one unit of study, which was 7 class periods long. Seven periods is not a long time for a population to gain statistically significant learning gains over another class that is learning the same material. Its possible that a longer treatment could result in more statistical gains in learning and engagement. The content of the unit is also a limitation. Science topics are not all viewed with the same interest as others. Astronomy could have been an interesting unit for some students, which could lead to higher engagement in and of itself. Other students could find astronomy to be a disengaging topic, which could have lead to lower engagement. This was not accounted for in this study.

A fifth limitation in this study is that the research did not account for any novelty effect created by the clickers. The clickers were new to all the students and the idea of using something new and different was appealing to all the students. Since the study was relatively short in duration this novelty effect could have accounted for increases in engagement. 
A sixth limitation of this study was that it did not account for the effects of just peer instruction. The lack of interviews from Classroom B about their attitudes towards peer instruction makes it difficult to compare the peer instruction between the two classes. A third classroom using neither the clickers nor the peer instruction would have been useful in determining how important the peer instruction was in the student engagement and learning.

\section{Recommendations}

This study looked at the possibility of clickers to increase student engagement and student learning in a secondary school. Although there was not strong statistical evidence to show the clicker's ability to do this there are still many potential benefits in using clickers. Engagement and learning increases may not be direct outcomes of using the clickers, but I do believe that a classroom that uses clickers is setting itself up to have higher academic success and student engagement. A number of the strategies that are associated with clickers are strategies that are present in successful classrooms. For example, clickers allow for frequent and easy checks for understandings and simple formative assessments. This allows for instructors to better understand what their students know and adapt classroom lectures and instruction accordingly. Additionally, clickers allow for a larger classroom response to a question while at the same time allowing this response to be anonymous.

One suggestion for a future study would be to look at the effect common clicker strategies, such as frequent formative assessments, high anonymous participation, and 
frequent kinesthetic interactivity, have on a secondary school science classroom. There are a number of strategies that lend themselves favorably to clickers. Any strategy or instruction method that involves student participation to a question can essentially be used with clickers. The benefit of these strategies with clickers would be the relative ease and speed that these strategies could be used. This study used peer instruction, which was an enjoyable strategy for the students and as the literature suggests (Beatty 2004, Beatty et al 2008, Crouch and Mazur 2001) is a strong strategy when coupled with clickers.

Future research could include studies to monitor engagement and attitude changes over longer periods of time. This could help determine how big of an impact the novelty effect of the clickers had on the students. It would also allow for students to use the clickers in multiple content units. More research on clickers coupled with effective teaching strategies needs to be done since this research shows that the physical use of the clicker may not be as important as the strategy that is being used with it. The real value in clickers may be the relative ease and speed that effective teaching strategies can be used with them.

Interactive technology in the classroom does show promise to create a more engaging and positive classroom environment. Student interviews and positive student perception towards the clickers leads the researcher to believe that the clickers do bring positive value to the classroom. The amount of value is hard to determine and may vary significantly between classrooms. 
Conclusion

In conclusion, this research does not provide statistical evidence to suggest that the use of clickers with peer instruction increases student learning gains. It does find slight statistical evidence to suggest students have increased engagement in class discussions when clickers are used. Qualitative data also suggests that students perceive the clickers to have a positive impact on them in the classroom. Through interviews students said that they enjoyed using the clickers. They said that they found class to be more engaging when clickers were used. Additionally, they thought they participated more and thought they were learning more when the clickers were coupled with peer instruction.

Overall, the findings in this research is in line with much of the current literature on clickers and peer instruction. Beatty et al. (2008) found that students and instructors who have used classroom response systems are mainly positive and enthusiastic about their effects on the classroom. This was in line with the findings of this research. The students were enthusiastic about the clickers and found them to be an enjoyable addition to the classroom. Martyn (2007) found that in her study using clickers there was no statistically significant learning outcome. Through a perception survey, however, she found that students perceive value in the use of clickers and would like to see their continued use in future classes. This is again in line with the findings of this research in which there were no statistically significant learning gains, but positive student attitudes were observed with the use of the clickers. 


\section{LIST OF REFERENCES}

Beatty, I. (2004). Transforming student learning with classroom communication systems. EDUCAUSE Center Appl. Res. (ECAR) Res. Bull., 2004(3), 1-13.

Beatty, I. D., Gerace, W. J., Leonar, W. J., and Dufresne, R. J. (2008). Designing effective questions for classroom response system teaching. Am. J. Phys. 74(1), 31-39.

Caldwell, Jane E., (2007). Clickers in the Large Classroom: Current Research and Best-Practice Tips. CBE - Life Sciences Education. 6(Spring) 9-20

Crouch Catherine H., Mazur, Eric. (2001). Peer Instruction: Ten years of experience and results. Am. J. Phys. 69(9), 970-977.

Galichon, J. P., \& Friedman, H. H. (1985). Cutting college classes: An investigation. College Student Journal, 19, 357-360.

Hug, Barbara, Krajcik, Joseph S.,Marx, Ronald, (2005). Using Innovative Learning Technologies to Promote Learning and Engagement in an Urban Science Classroom. Urban Education. 40(4), 446-472.

Knight, J.K., and Wood, W.B. (2005). Teaching more by lecturing less. Cell Biol. Educ. 4, 298310. 
Martyn, Margie (2007). Clickers in the Classroom: An Active Learning Approach. Educause Quarterly. 2, 71-74.

Narayan, J. S., Heward, W. L., Gardner, R., Courson, F. H., \& Omness, C. K. (1990). Using response cards to increase student participation in an elementary classroom. Journal of Applied Behavior Analysis, 23, 483-490.

Nichol, D. J., and Boyle, J. T. (2003). Peer instruction versus class- wide discussion in large classes: a comparison of two interaction methods in the wired classroom. Stud. Higher Educ. 28(4), :457- 473 .

Pemberton, Joy R, Borrego Jr, Joaquin, and Cohen, Lee M (2006). Using Interactive Computer Technology to Enhance Learning. Teaching of Psychology, 33:2, 145-147

Pollock, S. J. (2006). Transferring transformations: learning gains, student attitudes, and the impacts of multiple instructors in large lecture courses. AIP Conf. Proc. 818(1), 141-144.

Schrand, Tom, (2008). Tapping Into Active Learning and Multiple Intelligences with Interactive Multimedia. College Teaching. Spring, 78-84

Stowell, Jeffrey R., Nelson, Jason M. (2007) Benefits of Electronic Audience Response Systems on Student Participation, Learning, and Emotion. Teaching of Psychology. 34(4), 253258.

Wood, W. B. (2004). Clickers: a teaching gimmick that works. Dev. Cell 7(6), $796-798$. 
Zaremba, S. B., \& Dunn, D. S. (2004). Assessing class participation through self-evaluation: Method and measure. Teaching of Psychology, 31, 191-193. 
APPENDIX A

Assessments, Scoring Guide, Surveys, Interview Transcripts 


\section{Astronomy Unit Student Preassessment}

Answer the questions to the best of your ability. If you honestly do not know an answer write "I don't know." This assessment is to help us understand what it is you already know and what topics we should cover in our upcoming unit.

1a) In the picture below, draw how you think Earth moves.

b) List any forces you think are acting on the sun and Earth? What would happen if there were no forces acting on the Earth?

2. List all the planets in our solar system from closest to the sun to farthest. For each planet include any information you know about that planet. 
3. Give an explanation for why you think the Earth has seasons (winter, spring, summer, fall)? Include diagrams if you need to.

4. What is a galaxy? Do galaxies all have the same shape?

5. What is a star and what are stars made of? List any parts of a star's life cycle that you know.

6a) Why are there different phases of the moon? Name any phases of the moon that you know.

b) How does the moon influence the Earth? 
7a) What is the sun made of?

b) How big is the sun? You can use analogies if you'd like.

8. Define the universe.

Do you think the universe is changing? If so, explain how it could be changing.

9. Have you ever heard of the Big Bang Theory? Circle one:

Yes No

If yes, explain what you know about the Big Bang Theory. 


\section{Global Science - Astronomy Unit Test}

\section{Multiple Choice (1 pt each)}

Please do NOT write on the test

1. Which of the following planets in our solar system is classified as a ROCKY PLANET?
A) Venus
C) Jupiter
B) Uranus
D) Neptune

2. Why does the sun stay hot?
A) energy cannot escape
B) nuclear fission (atom nuclei breaking apart)
C) nuclear fusion (atom nuclei joining together)
D) energy leaves the sun, but it gets pulled back in

3. How are phases of the moon determined?
A) The shadow of the Earth on the moon
B) The shadow of the sun on the moon
C) The relative positions of the planets in our solar system
D) The relative positions of the Earth, sun, and moon.

4. How much of the moon is lit at all times?
A) None (0\%) of the moon is lit at all times
B) $25 \%$ of the moon is lit at all times
C) $50 \%$ of the moon is lit at all times
D) All (100\%) of the moon is lit at all times

5. You look out tonight and see a FULL MOON. How long until the next full moon occurs?
A) about 30 days
C) about 3 months
B) about 3 weeks
D) about 3 years

6. What planet fits this description? This rocky planet is the closest planet to the sun and smallest planet in our solar system.
A) Venus
C) Mercury
B) Mars
D) Pluto

7. What is the force that keeps planets in orbit around the sun and moons in orbit around a planet?
A) Orbital force
C) Frictional force
B) Gravitational force
D) Electrical force

8. The on Earth are a result of the moon's gravitational pull on the Earth.
A) Magnetic fields
C) Tides
B) Seasons
D) Weather patterns

9. According to the Big Bang theory, the universe is
A) shrinking and cooling
C) shrinking and warming
B) expanding and cooling
D) expanding and warming 
Use the Hertzsprung Russell Diagram below to answer questions 10 and 11

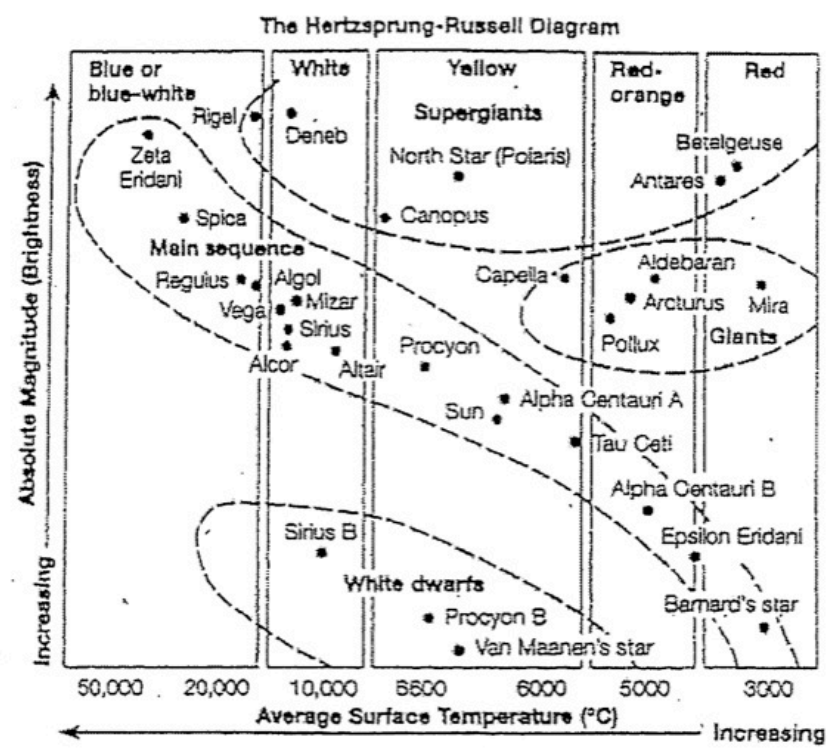

10. The Hertzsprung Russell Diagram uses what two criteria to classify stars?
A) Size and Temperature
C) Brightness and Type
B) Size and Brightness
D) Brightness and Temperature

11. What is the hottest Supergiant Star listed in the Hertzsprung Russell Diagram above?
A) Rigel
C) Spica
B) Sirius B
D) Deneb

12. Newton's Universal Law of Gravitation states influence the strength of gravity acting on two objects.
A) Density and Pressure
C) Velocity and Acceleration
B) Mass and Distance
D) Mass and Velocity

13. What gas is the sun primarily composed of?
A) Nitrogen
C) Helium
B) Hydrogen
D) Oxygen

14. Which of the following is NOT evidence for the Big Bang?
A) The universe is expanding (redshift)
B) The universe has a known temperature
C) The dinosaurs are extinct
D) The mix of the universe's elements is known

15. If the mass of the sun increased, the force of gravity acting between the Earth and sun would
A) not change.
C) decrease.
B) push the Earth farther from the sun.
D) increase. 
Matching (1 pt each)

16. Nebula

17. Supernova

18. White Dwarf

19. Black Hole

20. Main Sequence Star
A. A region of space having a gravitational field so intense that no matter or radiation can escape.

B. A cloud of gas and dust in outer space

C. Forms when a low-mass star has exhausted all its central nuclear fuel and lost its outer layers as a planetary nebula. Small in size, but very dense

D. Spends majority of time in this stage, nuclear reactions inside produce light and heat, our sun

E. A star that suddenly increases greatly in brightness because of a catastrophic explosion that ejects most of its mass.

\section{Ordering (1 pt each)}

Fill in the correct stage of the life cycle of a star in the diagram below

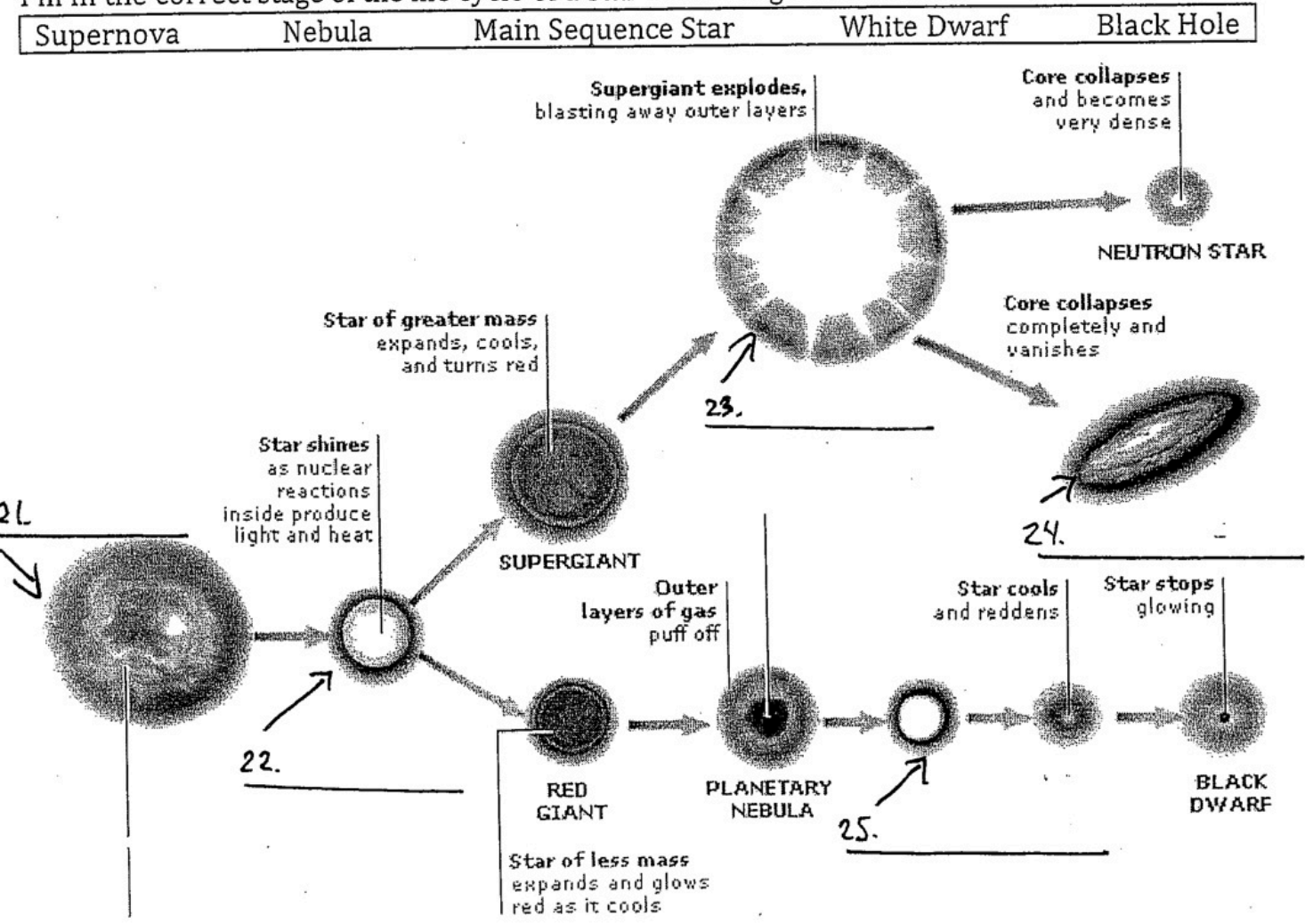


Classifications ( 1 pt each)

Classify each planet property description by writing either ROCKY planet or GAS planet

26. Planet can reach HIGH temperatures

27. Planet has many moons

28. Planet is relatively close to the sun

29. Planet has solid surface

30. Planet has a THICK atmosphere

Fill Ins (1 pt each)

\begin{tabular}{|lllll}
\hline Direct Sunlight & Indirect Sunlight & Craters & Maria & Tilt \\
\hline
\end{tabular}

31. The main reason for the Earth's seasons is because of the Earth's

32. In the summer season there is more

33. The dark patches on the moon, the are plains of dark solidified lava.

34. The on the moon were created as a result of impacts from left over debris during the formation of the solar system.

35. In the winter season there is more

\section{Short Answer (2 pts)}

Use the word bank below to put the 8 planets of our solar system in order from closest to the sun to farthest away.

\begin{tabular}{|lllc|}
\hline \multicolumn{4}{c|}{ Planets of Our Solar System: } \\
\hline Jupiter & Mercury & Earth & Neptune \\
Uranus & Saturn & Venus & Mars \\
\hline
\end{tabular}

\section{Label ( 2 pts)}

Correctly label the seasons for the Northern Hemisphere in the diagram below

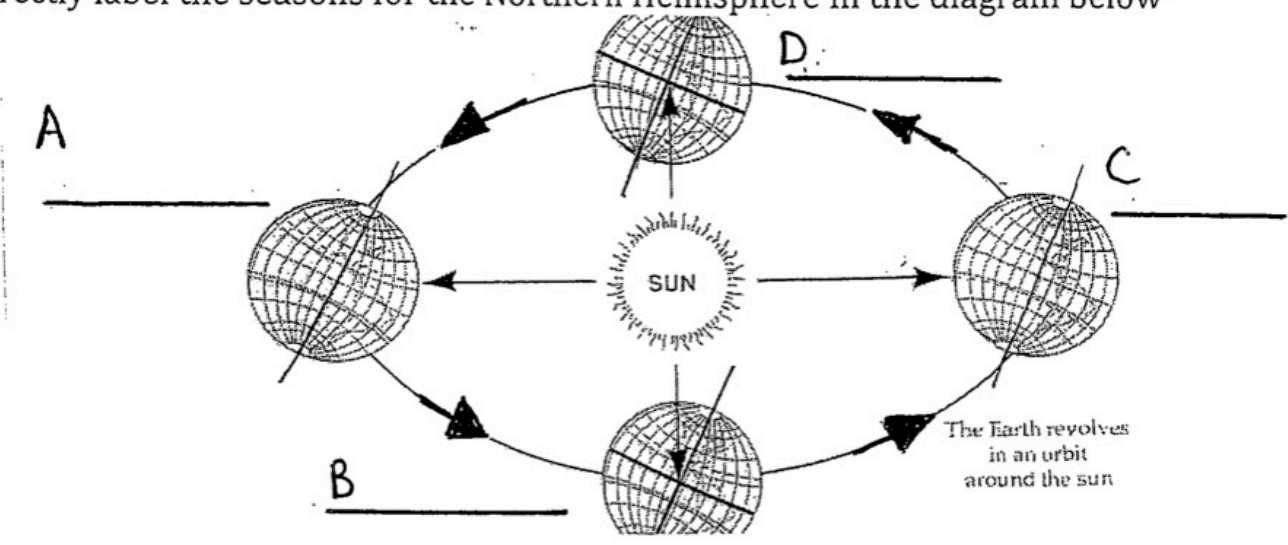


Date Period

\section{Astronomy Unit Test Answer Sheet}

1.

2.

3.

4.

5.

6.

7.

8.

9.

10.

11.

12.

36. Short Answer - 2 pts

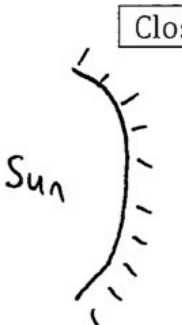

37. Label - 2 pts

Position A:

Position B:
13.

14.

15.

16.

17.

18.

19.

20.

21.

22.

23.

24.

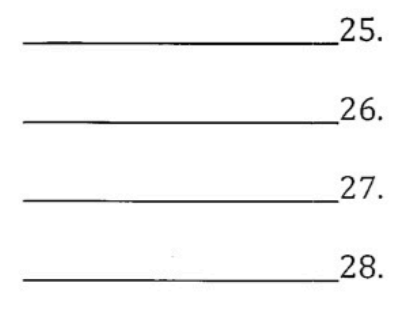

29.

30.

31.

32.

33.

34.

35.

27.

6.

8.

.




\section{Astronomy Unit Pre-Test - Post-Test Scoring Guide}

\section{Learning Objectives:}

1. Students will identify orbit systems and describe how gravity is the force that keeps planets and moons in orbit.

Pre-Test:

0 - Missing all info or incorrect diagram and no mention of gravity

1 - Includes correct diagram, may or may not mention gravity

2 - Correctly identifies gravity and how gravity affects the Earth

Post-Test Guide:

0 - No correct responses

1 - 1 correct response

2 - all correct responses

\begin{tabular}{|l|l|}
\hline Pre-Test Questions & 1 \\
\hline Post-Test Questions & $7,12,15$ \\
\hline
\end{tabular}

2. Students will identify and classify the bodies in our solar system based on properties and composition.

Pre-Test:

0 - Missing all info, includes a few random planets or properties

1 - includes all 8 planets in any order, none or a few properties

2 - includes all planets and correctly classifies them in order, includes properties

Post-Test Guide:

0 - No correct responses to 3 correct responses

1 - includes correct list of all planets in list and 4-5 correct answers

2 - includes correct list of all planets and 6-7 answers are correct

\begin{tabular}{|l|l|}
\hline Pre-Test Questions & 2 \\
\hline Post-Test Questions & $1,6,26,27,28,29,30,36$ \\
\hline
\end{tabular}


3. Students will explain why Earth experiences seasonal changes.

Pre-Test:

0 - Missing all info, minimal info

1 - Mentions tilt of Earth or direct sunlight

2 - Mentions tilt of Earth, direct sunlight, and diagram is correct

Post-Test Guide:

0 - No correct responses / 1 correct response

$1-2$ to 3 correct responses

2 - All responses are correct

\begin{tabular}{|l|l|}
\hline Pre-Test Questions & 3 \\
\hline Post-Test Questions & $31,32,35,37$ \\
\hline
\end{tabular}

4. Students will describe how the universe, galaxies, stars, and planets evolve over time.

Pre-Test:

0 - Missing all info

1 - Mentions minimal knowledge of the Big Bang, universe, and galaxies

2 - Mentions significant and correct info of the Big Bang, universe, and galaxies

Post-Test Guide:

0 - No correct responses

1 - 1 correct response

2 - All responses are correct

\begin{tabular}{|l|l|}
\hline Pre-Test Questions & 8,9 \\
\hline Post-Test Questions & 9,14 \\
\hline
\end{tabular}


5. Students will identify key properties of the sun, moon, and Earth.

Pre-Test:

0 - Identifies 0-1 of the following: correct reason for the phases of the moon / influences of the moon / sun's composition / relative size of the sun / energy source of the sun

1 - Identifies 2-3 of the following: correct reason for the phases of the moon / influences of the moon / sun's composition / relative size of the sun / energy source of the sun

2 - Identifies 4-5 of the following: correct reason for the phases of the moon / influences of the moon / sun's composition / relative size of the sun / energy source of the sun

Post-Test Guide:

$0-0$ to 3 correct responses

$1-4$ to 6 correct responses

$2-7$ to 8 correct responses

\begin{tabular}{|l|l|}
\hline Pre-Test Questions & $3,6,7$ \\
\hline Post-Test Questions & $2,3,4,5,8,13,33,34$ \\
\hline
\end{tabular}

6. Students will identify the different phases in the life cycle of a star.

Pre-Test:

0 - Identifies 0 phases of a stars life cycle

1 - Identifies 1-2 phases of a stars life cycle

2 - Identifies $3+$ phases of a stars life cycle

Post-Test Guide:

$0-0$ to 6 correct responses

$1-7$ to 9 correct responses

$2-10$ to 12 correct responses

\begin{tabular}{|l|l|}
\hline Pre-Test Questions & 5 \\
\hline Post-Test Questions & $10,11,16,17,18,19,20,21,22,23,24,25$ \\
\hline
\end{tabular}




\begin{tabular}{|l|l|}
\hline Pre-Test Questions & 1 \\
\hline Post-Test Questions & $7,12,15$ \\
\hline
\end{tabular}

\begin{tabular}{|l|l|}
\hline Pre-Test Questions & 2 \\
\hline Post-Test Questions & $1,6,26,27,28,29,30,36$ \\
\hline
\end{tabular}

\begin{tabular}{|l|l|}
\hline Pre-Test Questions & 3 \\
\hline Post-Test Questions & $31,32,35,37$ \\
\hline
\end{tabular}

\begin{tabular}{|l|l|}
\hline Pre-Test Questions & 8,9 \\
\hline Post-Test Questions & 9,14 \\
\hline
\end{tabular}

\begin{tabular}{|l|l|}
\hline Pre-Test Questions & $3,6,7$ \\
\hline Post-Test Questions & $2,3,4,5,8,13,33,34$ \\
\hline
\end{tabular}

\begin{tabular}{|l|l|}
\hline Pre-Test Questions & 5 \\
\hline Post-Test Questions & $10,11,16,17,18,19,20,21,22,23,24,25$ \\
\hline
\end{tabular}


Name Period Date April 22

On a scale of 1 (bad) - 5 (great) how do you think class discussions went today?

$\begin{array}{lllll}1 & 2 & 3 & 4 & 5\end{array}$

On a scale of 1 (bad) - 5 (great) how do you think you participated today?

$\begin{array}{lllll}1 & 2 & 3 & 4 & 5\end{array}$

Write down anything that you learned today: 
Name Period Date April 26

On a scale of 1 (bad) - 5 (great) how do you think class discussions went today?

$\begin{array}{lllll}1 & 2 & 3 & 4 & 5\end{array}$

On a scale of 1 (bad) - 5 (great) how do you think you participated today?

$\begin{array}{lllll}1 & 2 & 3 & 4 & 5\end{array}$

What is the force that keeps planets in orbit around the sun or moons in orbit around a planet?

What 2 factors determine the amount of gravity that is occurring between 2 objects?

1. 2.

Write down anything that you learned or found to be interesting today: 
Name

Period

Date

May 2

On a scale of 1 (bad) - 5 (great) how do you think class discussions went today?

$\begin{array}{lllll}1 & 2 & 3 & 4 & 5\end{array}$

On a scale of 1 (bad) - 5 (great) how do you think you participated today?

$\begin{array}{lllll}1 & 2 & 3 & 4 & 5\end{array}$

What are the two main causes of the seasons on Earth:

If it is winter in the Northern Hemisphere it is in the Southern Hemisphere. If it is summer in the Northern Hemisphere it is in the Southern Hemisphere. 
Name

Period

Date

May 4

On a scale of 1 (bad) - 5 (great) how do you think class discussions went today?

$\begin{array}{lllll}1 & 2 & 3 & 4 & 5\end{array}$

On a scale of 1 (bad) - 5 (great) how do you think you participated today?

$\begin{array}{lllll}1 & 2 & 3 & 4 & 5\end{array}$

Name two things that you learned about the sun today?

A star's life cycle depends on its This property determines the size, amount of energy released, and ultimately the fate of the star. 
Name

Period

Date

May 6

On a scale of 1 (bad) - 5 (great) how do you think class discussions went today?

$\begin{array}{lllll}1 & 2 & 3 & 4 & 5\end{array}$

On a scale of 1 (bad) - 5 (great) how do you think you participated today?

$\begin{array}{lllll}1 & 2 & 3 & 4 & 5\end{array}$

Name two things that you learned about the moon today?

What causes the phases of the moon? 
Name

Period

Date

May 10

On a scale of 1 (bad) - 5 (great) how do you think class discussions went today?

$\begin{array}{lllll}1 & 2 & 3 & 4 & 5\end{array}$

On a scale of 1 (bad) - 5 (great) how do you think you participated today?

$\begin{array}{lllll}1 & 2 & 3 & 4 & 5\end{array}$

Circle the correct italicized word(s):

According to the Big Bang Theory, the universe is expanding shrinking

and warming cooling.

Which of the following is NOT evidence for the Big Bang theory?

A. The universe has a measurable temperature

B. The mix of the elements is known

C. The dinosaurs are extinct

D. The universe is expanding 
Name

Period

Date

May 12

On a scale of 1 (bad) - 5 (great) how do you think class discussions went today?

$\begin{array}{lllll}1 & 2 & 3 & 4 & 5\end{array}$

On a scale of 1 (bad) - 5 (great) how do you think you participated today?

$\begin{array}{lllll}1 & 2 & 3 & 4 & 5\end{array}$

On a scale of 1 (not ready) - 5 (completely ready) how prepared do you feel for the test?

$\begin{array}{lllll}1 & 2 & 3 & 4 & 5\end{array}$

On a scale of 1 (have not started) - 5 (finished) how far are you on your project?

$\begin{array}{lllll}1 & 2 & 3 & 4 & 5\end{array}$




\begin{tabular}{|c|c|c|c|c|c|}
\hline $\begin{array}{l}\text { Survey Question: } \\
\text { Please circle one number: }\end{array}$ & $\begin{array}{l}\text { Disagree } \\
\text { Strongly }\end{array}$ & & Unsure & & $\begin{array}{l}\text { Agree } \\
\text { Strongly }\end{array}$ \\
\hline $\begin{array}{l}\text { 1. Participation with clickers and peer } \\
\text { instruction improved my grade in the unit. }\end{array}$ & 1 & 2 & 3 & 4 & 5 \\
\hline $\begin{array}{l}\text { 2. Participation with clickers and peer } \\
\text { instruction improved my understanding of } \\
\text { the subject content. }\end{array}$ & 1 & 2 & 3 & 4 & 5 \\
\hline $\begin{array}{l}\text { 3. Participation with clickers and peer } \\
\text { instruction increased my feeling of } \\
\text { participation in this class. }\end{array}$ & 1 & 2 & 3 & 4 & 5 \\
\hline $\begin{array}{l}\text { 4. Participation with clickers and peer } \\
\text { instruction increased my interaction with the } \\
\text { instructor. }\end{array}$ & 1 & 2 & 3 & 4 & 5 \\
\hline $\begin{array}{l}\text { 5. Participation with clickers and peer } \\
\text { instruction increased my interaction with } \\
\text { other students. }\end{array}$ & 1 & 2 & 3 & 4 & 5 \\
\hline $\begin{array}{l}\text { 6. I enjoyed activities that used clickers and } \\
\text { peer instruction. }\end{array}$ & 1 & 2 & 3 & 4 & 5 \\
\hline $\begin{array}{l}\text { 7. I would recommend using clickers and } \\
\text { peer instruction again in this class. }\end{array}$ & 1 & 2 & 3 & 4 & 5 \\
\hline
\end{tabular}

Please include any comments about using the clickers below: 


\begin{tabular}{|c|c|c|c|c|c|}
\hline $\begin{array}{l}\text { Survey Question: } \\
\text { Please circle one number: }\end{array}$ & $\begin{array}{l}\text { Disagree } \\
\text { Strongly }\end{array}$ & & Unsure & & $\begin{array}{l}\text { Agree } \\
\text { Strongly }\end{array}$ \\
\hline $\begin{array}{l}\text { 1. Participation with peer instruction } \\
\text { improved my grade in the unit. }\end{array}$ & 1 & 2 & 3 & 4 & 5 \\
\hline $\begin{array}{l}\text { 2. Participation with peer instruction } \\
\text { improved my understanding of the subject } \\
\text { content. }\end{array}$ & 1 & 2 & 3 & 4 & 5 \\
\hline $\begin{array}{l}\text { 3. Participation with peer instruction } \\
\text { increased my feeling of participation in this } \\
\text { class. }\end{array}$ & 1 & 2 & 3 & 4 & 5 \\
\hline $\begin{array}{l}\text { 4. Participation with peer instruction } \\
\text { increased my interaction with the instructor. }\end{array}$ & 1 & 2 & 3 & 4 & 5 \\
\hline $\begin{array}{l}\text { 5. Participation with peer instruction } \\
\text { increased my interaction with other students. }\end{array}$ & 1 & 2 & 3 & 4 & 5 \\
\hline $\begin{array}{l}\text { 6. I enjoyed activities that used peer } \\
\text { instruction. }\end{array}$ & 1 & 2 & 3 & 4 & 5 \\
\hline $\begin{array}{l}\text { 7. I would recommend using peer instruction } \\
\text { again in this class. }\end{array}$ & 1 & 2 & 3 & 4 & 5 \\
\hline
\end{tabular}

Please include any comments about peer instruction below: 
Interview Questions

1. Do you like science classes? Why or why not?

2. What do you think about the unit that we just studied?

3. What was your favorite component of the unit?

4. What activities did you enjoy the most?

5. Did you enjoy using the clickers?

6. What about them did you like/dislike?

7. Do you think that doing the peer instruction activities with clickers helped you learn more?

8. Why or why not?

9. What would you change about the way the clickers used in the classroom?

10. What would you keep the same?

11. What could we do in class to make it more interesting and engaging for you? 
Interview 1

Bold type is the researcher, italicized type is the student

In general do you like science classes?

Yeah.

You do? Why do you like them.

They are just interesting.

Ok. They are interesting. Did you like the astronomy unit that we just did?

Yeah it was really cool.

Did you know a lot about astronomy ahead of time?

Yeah I knew some, my grandma is really big on it.

So you have a little bit of background?

Yeah.

What was your favorite thing about the unit?

The whole black dwarf thing.

Ok so the stars and their life cycle?

Yeah that stuff.

What were some of the activities that you liked doing the most?

The moon phases one.

Do you like doing group work then or working by yourself?

Group work. 
Group work. And as far as using the clickers did you like using those?

Yeah.

Did you think they were beneficial to the class?

Yeah.

Do you think they made you participate more?

Yeah.

Whenever we did a question and then we saw the distribution of the class and then I had you guys redo it, do you think that was useful?

Yeah. It gave me a chance to get it right.

Ok. So what would you say was your favorite thing about the clickers then?

Just playing with them.

Do you think that process of having the question with the clickers and then talking it over with someone after you see the answers, do you think that helped you learn more?

Yeah.

How come?

It just gave more room for error.

Ok. Would you change anything about the way you used them or would you like to use them in different ways?

No. They would be cool and useful for all classes and stuff.

Ok, so you wish they used them in all classes?

Yeah.

And then finally for science class or this particular class what could I do to make it even more interesting or more engaging?

More labs. 
So you like the labs a lot?

Yeah

Do you think it would be cool if I incorporated the clickers with labs somehow, maybe as you were going along to check for different things?

Yeah, that would be great.

Alright, thanks a lot.

Interview 2

Bold type is the researcher, italicized type is the student

In general do you like science class?

Its pretty interesting, I enjoy it.

Ok you do? What do you like about it?

I like learning things about astronomy. I like astronomy. Any other subject I don't like. Any other topics are kind of boring, but astronomy is really interesting.

So in general, some topics in science you don't like, but when we did astronomy you thought that was interesting?

Yeah.

So what was your favorite thing that we did in that unit?

The flashlight thing.

The moon? The moon phases?

Yeah.

Ok so in general what type of activities do you like doing in science?

I like doing labs. 
Labs? What about doing reading or things like that?

No.

Do you like working in groups?

Yes.

Ok group work. Talking about the clickers, did you like using those in class?

Yeah they were pretty great. It helped answer the question better.

So it made you participate more?

Yeah.

Do you like you learned more by using them?

Yeah.

So whenever we would do a clicker question and you'd see other people's responses and then I'd ask you to work with someone else and see if they could convince you...?

Yeah it helped better.

That helped better? So do you think doing that process helped you learn better?

In a way.

What do you mean in a way?

It was better than actually... it did...because huh, sorry, yeah it did help.

Ok so it did?

Yeah.

Just a couple questions left. So what would you change about the clickers in the class? Would you change anything?

No.

So you liked the way it was used? 
Yeah.

So you'd consider keeping things the same way? You liked the way we used them?

Yeah.

And finally, in a science class, the clickers are a kind of interactive technology. Do you like using technology in science classrooms?

Yeah.

Is there any way we could make science class more interesting or engaging for you? Any particular types of activities or technology anything like that?

Use the laptops more and do more labs.

Alright well thank you very much.

Interview 3

Bold type is the researcher, italicized type is the student

In general do you like science class?

No.

You don't? What don't you like about it?

Well I do, but sometimes it gets boring.

It's boring? Ok, are there any particular activities that you think are more boring?

No. Just fire stuff is cool.

Fire stuff?

Yeah fire and mixing stuff.

Ok. Well we just did our astronomy unit. What did you think about that unit? Did you think it was interesting? Boring? 
It was interesting.

What was your favorite thing about the unit?

Umm I don't know. Nothing really. It was boring, but it was somewhat interesting.

Ok. Were there any particular activities that you liked doing in that unit on any given day?

I liked doing the clickers.

Ok. So you liked doing the clickers. What did you like about them?

You push buttons and don't have to put it on paper. You just do it.

Did you like when I would have you guys answer a question and you'd see the rest of the classes and then I'd ask you to work with someone else and try to maybe convince each other or talk it over?

Yeah.

Was that helpful?

Yeah.

How did it help you?

Cause they would explain to you why it was an answer and stuff like that.

Ok. So you liked using the clickers. Do you think you learned more by using the clickers?

Yeah. Because you are talking about it more. So if someone would switch to a different answer and they could tell us why it was different.

Ok. Do you feel like in class you were able to participate more using the clickers?

Yeah cause everyone is equal.

Did you like that you could put in an answer and even if you were wrong no one would know so you wouldn't be embarrassed?

Yeah. 
Ok just a couple questions left. So would you change anything about the way we would use the clickers in the class?

No. Well I think it would be cool to take a test with the clickers.

Yeah that is another feature that we didn't do, but I think could be interesting as well. Finally, what could I do in class to make it more interesting or engaging for you?

Nothing.

Nothing?

No, I am already engaged.

You are already engaged in it. Do you like using technology and interactive stuff in class?

Yeah.

Do you think if we did more stuff like that you'd be more interested in class? So if we used clickers more, computers more, just technology in general, you think it would benefit the class to be used more?

Yes.

Ok thank you.

Interview 4

Bold type is the researcher, italicized type is the student

So in general, would you say you like science class?

Yeah.

Ok. How come?

Umm, I don't know. I always learn something new. Its fun.

Ok. So what do you think about our astronomy unit that we just did? 
I think that it was really cool learning about planets. I learned about Jupiter. I liked learning about a new planet cause I didn't know anything about it.

So you liked it? Got to learn some new things?

Yeah.

So what was your favorite component of that unit?

I have no idea.

You don't know? Was there any particular thing we did in class or activities or topics?

Probably learning about the Big Bang Theory.

Ok. Yeah the Big bang is interesting. As far as activities or things we did in class every day, what things did you like the most or dislike?

I liked when we used the clickers.

You liked that?

Yeah.

Ok what did you like about them?

Cause you could ask the people around us to help us understand. They would help me change my mind so if I didn't know it I would know it by the end.

Ok. So you liked the fact that when I would ask a question and then you got to see the whole classes distribution and then I would say ' $O \mathrm{k}$ now do it again and see if the person next to you can change your mind or you can change their mind.' You thought that was helpful?

Yeah.

Ok. So do you think that you learned more because of doing that?

Yeah.

Do you think you participated more?

Probably yeah. 
Do you think that it was more engaging to be in class and sitting there in lecture and being able to participate with those...(interrupted)

Yeah because we actually got to do something instead of just sitting there.

Ok. So you liked the way we used them in class?

Yeah.

So do you have any suggestions about how we could use them in a different way?

No.

Ok that's fine. Just a couple last questions. In a science class, what are ways that we could make it more interesting or get you more engaged or get you to participate more? What types of things could I do to make it more fun?

Break up into groups more.

Ok more group work? And as far as technology in the class, do you like using technology? If we used the clickers more often or computers more often do you think it would be beneficial and help you learn more?

Yeah.

Ok. Thank you. 
APPENDIX B

Human Subjects Approval and Application 
HSRRC Application Proposal

\author{
Andrew Mankowski \\ Portland State University \\ Center for Science Education
}

See attached form

\title{
I. Investigator's Assurance
}

\section{Project Title and Prospectus}

Do "Clickers" Improve Student Engagement and Learning in Secondary Schools? One recent form of interactive technology that incorporates active student participation is the Classroom Response System commonly called the "clicker." Clickers are handheld devices, similar in size to a television remote control, that allow students to press buttons and transmit instant individual responses to questions posed by an instructor. They have shown potential to increase student engagement, performance, and participation in the classroom when used effectively. Peer instruction, a type of student to student interaction in which pairs or small groups of students discuss their answers to questions before responding, is often used in conjunction with clickers, and may account for the perceived effectiveness of these tools. The purpose of this study is to determine the effectiveness of clickers in secondary classrooms, controlling for their use during peer instruction. Two classrooms will be examined ( $\mathrm{n} \sim 30$ for each classroom) in which 1 classroom will use clickers integrated with peer instruction activities, while the other classroom will only do the peer instruction activities. The researcher hopes to find data to help answer the question: "Are clickers that are used with peer instruction activities effective at improving student learning gains and increasing student engagement in secondary schools?" The study will test the hypothesis that the inclusion of the clickers will indeed result in increases in student performances and student engagement even when controlling for peer instruction. This study will add to clicker research at the secondary school level.

\section{Exemption Claim for Waiver of Review}

This research falls in the waived review category under:

1. Research conducted in established or commonly accepted educational settings, involving normal educational practices, such as (i) research on regular and special education instructional strategies, or (ii) research on the effectiveness of or the comparison among instructional techniques, curricula, or classroom management methods.

This research will be conducted in a regular public secondary school science classroom setting. The research involves common instructional strategies and compares the effectiveness of them when incorporating a new technology, the Classroom Response System. All testing information from this study is confidential.

\section{Subject Recruitment}




\section{Subject Population}

The subjects in this study are high school students in an integrated sciences classroom at Milwaukie High School. Two classrooms will be studied, a control group $(\mathrm{n} \sim 30)$ and a treatment group $(\mathrm{n} \sim 30)$. The students will generally be freshmen in high school, ages 14 -15 . The population is of approximately equal numbers of male and female. The researcher expects there to be a mix of ethnic backgrounds including Caucasian, African American, Latino, and Asian American. The students will be from a general education class and should be in good health.

\section{Subject Selection}

Two freshmen level high school science classes from the researcher's student teaching placement will determine the subject selection.

\section{Informed Consent}

The subjects in this study are freshmen high school students, aged $14-15$, and therefore fall into the child subject category. There will be a written informed consent form to be signed by the parent/guardian of each student. This letter will be given to the student at school by the researcher. The student will be asked to bring it home and have it reviewed by a parent/guardian and signed in order for the student to participate in the study. The informed consent form is included at the end of this application.

\section{First Person Scenario}

\section{Viewpoint from Treatment Group Student}

I received a letter from the student teacher in my science class. It explained that he was doing research to see the effectiveness of a new teaching strategy involving a new technology called the Classroom Response System (clicker). The letter explained the research so my parents would be aware of it and allow me to participate. The student teacher had us take a pretest about our knowledge of the subject material our next unit was on. For the next few weeks while we were learning about this unit, the teacher would have us use the clickers to monitor our responses to questions. We would answer a question with the clicker, and then we would discuss our answer in small groups, this is what our student teacher called the peer instruction strategy. After the discussion we would re-answer the same question with our clicker and the student teacher would show us the correct response. We would then talk about the question, the answer, and the concept during a class discussion. We were never graded on our responses, but were encouraged to answer them the best we could using the knowledge we had been learning in the class. We would do this process one or two times per day. At the end of the unit we were given an attitude survey about how we liked this teaching strategy and how we liked using the clickers. A few of us were randomly selected by the student teacher to answer some interview questions in more detail.

\section{Viewpoint from Control Group Student}

I received a letter from the student teacher in my science class. It explained that he was doing research to see the effectiveness of a new teaching strategy involving a new technology called the Classroom Response System (clicker). The letter explained the 
research so my parents would be aware of it and allow me to participate. The student teacher had us take a pretest about our knowledge of the subject material our next unit was on. Sometimes during class our teacher would ask a big concept question and have us answer it in our lab notebooks. We would write down our answer and then we would discuss our answer in small groups, this is what our student teacher called the peer instruction strategy. After the discussion we would re-answer the same question in our lab notebooks and the student teacher would show us the correct response. We would then talk about the question, the answer, and the concept during a class discussion. We were never graded on our responses, but were encouraged to answer them the best we could using the knowledge we had been learning in the class. We would do this process one or two times per day. At the end of the unit we were given an attitude survey about how we liked this teaching strategy. A few of us were randomly selected by the student teacher to answer some interview questions in more detail.

\section{Potential Risks and Safeguards}

There is minimal to no risk involved for the students in this study. The research being conducted is taking place in an established educational setting. All student responses will remain confidential and all students and their guardians have the choice to opt out of the research. Student responses will be presented in the research anonymously. During the interviews the students responses will be audio recorded. This may cause some students to feel uneasy or embarrassed. However, the researcher will give the student the choice to opt out of an interview if they do not want to be audio recorded. Additionally students will be reminded of the confidentiality of their responses.

\section{Potential Benefits}

The researcher hopes that this study will help answer the question "Are clickers that are used with peer instruction activities effective at improving student learning gains and increasing student engagement in secondary schools?" The researcher wants to find a strategy that gets students interested and engaged in learning science, while at the same time increasing their conceptual knowledge at the secondary level. The benefits include a possible effective strategy that both engages more students in the science classroom and has more students learn the conceptual knowledge surrounding the science material being taught. This could be very beneficial for science teachers looking for new ways to engage their class, incorporate an interactive technology, and increase their students' learning gains.

\section{Records and Distribution}

Student responses to answers during the clicker and peer instruction activity will remain confidential. Each student is assigned a number with their clicker, which records their answers into the computer. When a question is answered with the clicker only the student answering and the teacher will know how the student responds. This anonymity factor makes it so other students do not know how other students are answering. Students will randomly be assigned their clicker number and this is how the researcher will maintain the confidentiality of any data each student provides to this study. Only the researcher and each individual student will know their respective number. All pre/post 
test and attitude survey answers will remain confidential. Post-tests will be returned to students with feedback from the teacher, but the researcher will create photocopies.

Students' responses during the class discussion portion of a peer instruction session will also remain confidential to the confines of that class. Interviewed students will be audio recorded and any responses during these recordings will remain confidential and appear under the student's assigned number in any written research summary or report. All digital data will be stored and maintained on a password-protected computer and all paper data will be in a locked filing cabinet. It will be accessible by the researcher. Any data that includes student responses will be analyzed during the spring/summer of 2011 . After the research is analyzed, compiled, and completed the individual student data will be destroyed after three years as required by federal law. After the audiotapes are transcribed the audio recordings will be destroyed after three years as required by federal law.

See the following attached forms:

\section{Appendices}

Informed Consent

Student Attitude Survey

Interview Questions 
Informed Consent

Title of Research: Do “Clickers” Improve Student Engagement and Learning in Secondary Schools?

Investigator: Andrew Mankowski - Portland State University graduate student, Global Science student teacher

Before allowing your child to participate in this research study, it is important that you read the following explanation of this study. This statement describes the purpose, procedures, benefits, risks, discomforts, and confidentiality of the research. Also described is your right to withdraw from the study at any time. No guarantees or assurances can be made as to the results of the study.

Purpose of Study and Explanation of Procedures

One recent form of promising interactive technology that incorporates active student participation is the Classroom Response System commonly called the "clicker." Clickers are handheld devices, similar in size to a television remote control, that allow students to press buttons and transmit instant individual responses to questions posed by an instructor. They have shown potential to increase student engagement, performance, and participation in the classroom when used effectively. Peer instruction, a type of student to student interaction in which pairs or small groups of students discuss their answers to questions before responding, is often used in conjunction with clickers, and may account for the perceived effectiveness of these tools. The purpose of this study is to determine the effectiveness of clickers in secondary classrooms, controlling for their use during peer instruction.

Participants in this study will use peer instruction educational strategies surrounding key conceptual questions 1-2 times each class period during an upcoming $\sim 5$ week unit. One group of students will use clickers during these instructional strategies, while the other group will not. Students will be asked to keep a reflective journal about these activities and will be given a few minutes each day to write in them. At the end of the study participants will be asked to take a short 7 question attitudes and perceptions survey ranking what they thought of the strategies. Additionally approximately 10 students will be selected at random to be interviewed about the peer instructional strategies and the clickers.

$\underline{\text { Risks and Discomforts }}$

Your child will not be at physical or psychological risk and should experience no discomfort resulting from the research procedures.

$\underline{\text { Benefits }}$

The researcher hopes to find support that classrooms using peer instruction activities coupled with classroom response systems have increased student engagement and learning gains. The benefits would then be a potential classroom strategy that can help raise engagement levels and learning when appropriately used.

\section{Confidentiality}

All information gathered from the study will remain confidential. Your child's identity as a participant will not be disclosed to any unauthorized persons; only the researchers and Portland State University IRB will have access to the research materials, which will be kept in a locked drawer. Any references to your child's identity that would compromise his/her anonymity will be removed or disguised prior to the preparation of the research reports and publications. Any audiotapes will be destroyed after the required time allowed by federal law. Last names will not be used in the transcripts of any recording.

Withdrawal Without Prejudice

Participation in this study is voluntary; refusal to participate will involve no penalty. Each participant is free to withdraw consent and discontinue participation in this project at any time without prejudice from this institution.

Questions

Any questions concerning the research project can be directed at the researcher Andrew Mankowski. Parents, guardians, or participants can call 414-803-4326 or email at ajmankowski@gmail.com

\section{Agreement}

This agreement states that you have received a copy of this informed consent. Your signature below indicates that you agree to your child's participation in this study.

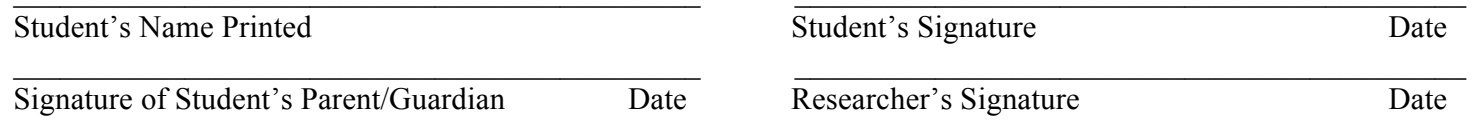


Human Subjects Research Review Committee

Post Office Box 751

Portland, Oregon 97207-0751
$503-725-4288$ tel

503-725-3416 fax

hsrrc@lists.pdx.edu

December 10, 2010

To: Andrew Mankowski

From: Mary Oschwald, HSRRC Chair

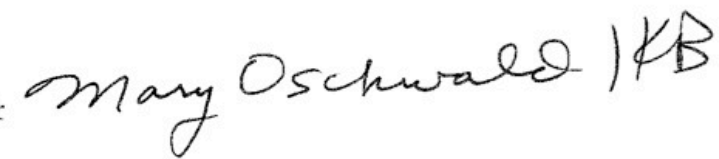

Re: Approval of your application titled, "Do "Clickers" Improve Student Engagement and Learning in Secondary Schools?" (HSRRC Proposal \# 101535).

Dear Andrew,

In accordance with your request, the Human Subjects Research Review Committee has reviewed your proposal referenced above for compliance with DHHS policies and regulations covering the protection of human subjects. The committee is satisfied that your provisions for protecting the rights and welfare of all subjects participating in the research are adequate, and your project is approved. Please note the following requirements:

Changes to Protocol: Any changes in the proposed study, whether to procedures, survey instruments, consent forms or cover letters, must be outlined and submitted to the Chair of the HSRRC immediately. The proposed changes cannot be implemented before they have been reviewed and approved by the Committee.

Continuing Review: This approval will expire on December 10.2011. It is the investigator's responsibility to ensure that a Continuing Review Report (available in ORSP) of the status of the project is submitted to the HSRRC two months before the expiration date, and that approval of the study is kept current.

Adverse Reactions: If any adverse reactions occur as a result of this study, you are required to notify the Chair of the HSRRC immediately. If the problem is serious, approval may be withdrawn pending an investigation by the Committee.

Completion of Study: Please notify the Chair of the Human Subjects Research Review Committee (campus mail code ORSP) as soon as your research has been completed. Study records, including protocols and signed consent forms for each participant, must be kept by the investigator in a secure location for three years following completion of the study.

If you have questions or concerns, please contact the HSRRC in the Office of Research and Sponsored Projects (ORSP), (503) 725-4288, 6th Floor, Unitus Building, 4th \& Lincoln.

Cc: Michael J. Flower 